\title{
Comercio y alojamiento en Madīnat Mursiya. Estudio arqueológico de los fanādiq andalusíes en Murcia
}

\author{
Trade and accommodation in Madinnat Mursiya. Archaeological study of the \\ Andalusian fanādiqs in Murcia
}

Alicia Hernández Robles ${ }^{1}$

Recibido: $1 / 03 / 2021$

Aprobado: 8/04/2021

Publicado: $15 / 07 / 2021$

\begin{abstract}
RESUMEN
El estudio histórico del funduq en al-Andalus muestra que estos edificios, utilizados como almacén y posada, fueron un espacio habitual de las ciudades andalusíes. Sin embargo, su caracterización arqueológica es más reciente y continúa en marcha con el estudio y revisión de los restos arqueológicos que pueden interpretarse como funduq. En el presente artículo exponemos los restos arqueológicos de la ciudad de Murcia que han sido interpretados como fanādiq (pl. de funduq) o edificios públicos, o restos que podrían ser interpretados como tal a los que no se les atribuyó una funcionalidad concreta. A partir del análisis de los restos arqueológicos de estos edificios, de las características generales de los fanādiq, determinadas a partir de la información que han proporcionado otras excavaciones arqueológicas de la península Ibérica, y del estudio del urbanismo de la ciudad de Murcia, planteamos una propuesta de interpretación o reinterpretación de los casos de estudio murcianos.
\end{abstract}

Palabras Clave: funduq, al-Andalus, comercio, Murcia, arqueología medieval.

\section{INTRODUCCIÓN}

En la ciudad islámica distintos espacios y edificios estaban relacionados con el comercio. En los zocos y las alcaicerías se practicaba la venta al por menor, para el abastecimiento habitual e interno de la ciudad, y solían distinguirse según el tipo de producto vendido. Por otro lado, el funduq estaba destinado a la venta al por mayory a la recepción de mercancías del exterior de la ciudad, ligado al comercio exterior

\section{ABSTRACT}

The historical study of the fundug in al-Andalus reveals that these buildings, used as warehouse and inn, were usual within the Andalusian cities. However, their archaeological characterization is more recent and is still ongoing with the examination and review of the archaeological remains that could be interpreted as funduq. This article studies the archaeological remains from the city of Murcia which have been interpreted as fanādiq (plural of funduq) or public buildings, as well as the archaeological remains without a clear interpretation but which might be interpreted in such way. From the analysis of the archaeological remains of these buildings, the general characteristics of the fanādiq, established from the information gathered from other archaeological excavations within the Iberian Peninsula and the study of the urbanism of the city of Murcia, we are presenting a proposal of interpretation or reinterpretation of the case studies from Murcia.

Keywords: funduq, al-Andalus, trade, Murcia, Medieval Archaeology.

o de larga distancia. En él se hospedarían también los viajeros y comerciantes que llegaban a la ciudad (CHALMETA, 1973: 117-119). Además, en espacios abiertos de la ciudad podrían tener lugar mercados itinerantes u ocasionales.

El funduq es el objeto de estudio del presente artículo a través de las excavaciones arqueológicas realizadas de estas estructuras en la ciudad de Murcia. El estudio arqueológico de los fanādiq (plural de funduq) en al-Andalus

\footnotetext{
1. Departamento de Prehistoria, Arqueología, Historia Antigua, Historia Medieval y Ciencias y Técnicas Historiográficas, Universidad de Murcia, Campus de La Merced, 30001 Murcia, España. Los resultados aquí expuestos forman parte de la tesis doctoral en marcha financiada por el Programa Predoctoral FPU del Ministerio de Ciencia, Innovación y Universidades (FPU16/00218). Este trabajo se ha realizado en el marco del proyecto I+D+i Los orígenes de la presencia italiana en Murcia (siglos XII al XV) (2019-2022, cod. 20896/ $\mathrm{PI} / 18$ ) de la Fundación Séneca (Agencia Regional de Ciencia y Tecnología, CARM) y del Convenio de colaboración entre el Excmo. Ayuntamiento de Murcia y la Universidad de Murcia para la investigación científica, formación, puesta en valor y difusión del Yacimiento Arqueológico de San Esteban.
}

Cómo citar: Hernández Robles, A. (2021): Comercio y alojamiento en Madinat Mursiya. Estudio arqueológico de los fanādiq andalusíes en Murcia. Arqueología Y Territorio Medieval, 28. e6186. https://doi.org/10.17561/aytm.v28.6186 
se mantuvo como un aspecto marginal hasta los últimos años de la década de los 90. Hasta ese momento no se habían documentado estos edificios en contexto arqueológico y solo se contaba con el al-funduq al-ŷadíd de Granada, de época nazarí, conocido como Corral del Carbón, como único caso de funduq conservado (TORRES, 1946). Progresivamente, el estudio histórico de estos edificios ha ido aportando datos a partir de las fuentes documentales árabes y cristianas, en cuanto al uso y funcionamiento de este tipo de edificios, su ubicación y número en las ciudades (JIMÉNEZ, 2019). Los libros del Repartimiento conservados del momento de la conquista cristiana de ciudades como Valencia, Murcia o Málaga informan de la existencia de estas infraestructuras en las ciudades andalusíes. No ha sido hasta la publicación de la obra de O. R. Constable (2003) cuando se han aglutinado todos estos aspectos realizando un estudio global de la institución islámica del funduq y planteando su desarrollo de forma diacrónica.

En lasúltimas décadas, restos devarias excavaciones de la ciudad de Murcia han sido propuestos como posibles fanādiq. Sin embargo, esta hipótesis suele aparecer planteada como una más de entre otras posibilidades, como que se tratara de otro tipo de edificios públicos. En otros casos, a estos restos no se les ha atribuido una funcionalidad concreta. El objetivo del presente trabajo es realizar una síntesis de los espacios identificados arqueológicamente en la ciudad de Murcia que pueden ser interpretados como fanādia para conocer mejor este tipo de edificio comercial y su presencia en la medina islámica. Para ello se presenta, en primer lugar, una breve introducción a la institución del funduq andalusí y su relación con otros edificios comerciales como las alhóndigas. En segundo lugar, se plantean las características generales del funduq a partir de la información que ha proporcionado su hallazgo en otras excavaciones arqueológicas de la península Ibérica. Posteriormente, se describen los restos arqueológicos hallados en Murcia, contextualizándolos en el urbanismo de Madīnat Mursiya, y se analizan en función de sus similitudes y diferencias con los ejemplos de este tipo de edificios en otras ciudades andalusíes.

Con respecto a la metodología llevada a cabo para el presente estudio, se ha realizado el análisis arqueológico de los restos hallados revisando las excavaciones arqueológicas de edificios a los que se les ha atribuido un uso público y comercial como funduq o alhóndiga en Murcia; para ello se recurrió a las memorias finales de excavación depositadas en el Archivo General de la Región de Murcia de aquellos casos en los que habían sido entregadas. Para contrastar y comparar los restos hallados en Murcia con otros fanādiq se recurrió al estudio de las excavaciones de funduq o alhóndigas en otras ciudades andalusíes.

\section{EL FUNDUQ EN AL-ANDALUS: DE LA DENOMINACIÓN A SUS RESTOS MATERIALES}

Tradicionalmente se ha definido al funduq como el establecimiento comercial que servía de alojamiento para viajeros y mercaderes, estructurado en torno a un patio central y construido con materiales y técnicas poco ostentosas. En él se contaba con espacios de almacén y cuadras en la planta baja, quedando la planta superior como zona de alojamiento (TORRES, 1946; CHALMETA, 1973: 137-143).

Habitualmente encontramos conceptos como jān, funduq, alhóndiga, alfondech o caravasar, bien como sinónimos o como traducciones de un idioma a otro, para hacer referencia, aparentemente, a un mismo tipo de edificio. Nombran el lugar que daba alojamiento a viajeros, mercaderes y peregrinos, en rutas o en ciudades, donde poder avituallarse y almacenar sus mercancías. Sin embargo, debemos tener en cuenta que cada uno de estos términos surgió en momentos y territorios concretos, generando usos distintos y dando nombre a diferentes infraestructuras. Por lo tanto, aunque todos ellos compartieran ciertas características arquitectónicas y/o funcionales, debido en parte al origen oriental común a 
todos ellos, consideramos que no podemos obviar que tuvieron usos y desarrollos distintos (TORRES, 1946; CONSTABLE, 2003: 4-5) y que esta variedad de términos implica el uso y la adopción de estos edificios en diferentes contextos culturales y lingüísticos.

Para el caso que nos ocupa, nos centraremos en los conceptos de funduq, alhóndiga y alfondech en el contexto medieval de la península Ibérica. El estudio de estas instituciones nos ha llevado a entender el funduq como la institución árabo-islámica que servía como posada y almacén a viajeros y comerciantes en territorio islámico. El edificio era controlado por los poderes islámicos y acogía a viajeros y comerciantes de cualquier procedencia. Contaba con distintas zonas como espacios de almacén o lugares en los que exponer las mercancías, donde se llevarían a cabo transacciones comerciales de venta al por mayor entre comerciantes locales de la ciudad y los extranjeros instalados en el funduq (CONSTABLE, 2003: 88-100). El tamaño y la calidad de las estructuras de estos edificios podía ser muy variada. Las instalaciones no eran tan cómodas como las de una vivienda, siendo sus principales diferencias con esta los sistemas de iluminación, ventilación y saneamiento. Las habitaciones abrían a un patio central, y no estaban conectadas entre sí. La planta baja carecía de aperturas al exterior para garantizar una mayor seguridad a los usuarios y sus mercancías.

El término alhóndiga es la castellanización del árabe funduq, de su uso como palabra determinada con artículo: al-funduq (TORRES, 1946: 447; CHALMETA, 1973: 137139). Lo encontramos en documentos históricos desde el siglo XI haciendo referencia a edificios de alojamiento y almacenamiento, bien como edificios de nueva construcción o aludiendo a alhóndigas ya en funcionamiento tras la conquista ${ }^{2}$ (TORRES, 1946: 448; CONSTABLE, 2003: 127, 168-169). Estas menciones muestran que la institución del funduq fue adoptada en territorios cristianos como alhóndiga, así como que algunos fanādiq andalusíes siguieron en funcionamiento tras la conquista cristiana de los territorios peninsulares. A partir del siglo XIII, la alhóndiga tuvo un desarrollo y características propias. Se distinguió del funduq por ser un edificio ubicado en territorio cristiano, controlado por la corona de Castilla, en el que predominó la función de almacén a la vez que servía como lugar para el pago de impuestos, control y venta de productos que llegaban a la ciudad, especialmente del trigo (TORRES, 1946: 469). En territorios de la Corona de Aragón se produjo un fenómeno similar con el alfondech. Este edificio fue distinguiéndose del funduq islámico introduciendo una serie de cambios, destacando su uso principalmente como alojamiento (CONSTABLE, 2003: 164-165). Dada la relación y la continuidad de la institución islámica con la cristiana, estos cambios pueden ser entendidos como una evolución y adaptación del edificio islámico al nuevo contexto cultural cristiano

En consecuencia, según la cronología de los restos arqueológicos abordados en el presente trabajo, los siglos XII y XIII, y el control islámico de la ciudad de Murcia en ese periodo, de aquí en adelante utilizaremos el término funduq para hacer referencia a los restos arqueológicos interpretados como edificios públicos comerciales en los que viajeros y comerciantes podían alojarse.

A continuación, procederemos a caracterizar los fanādiq andalusíes a partir de la información que han proporcionado las estructuras en excavaciones arqueológicas que han sido interpretadas como funduq o alhóndiga en las últimas décadas, aproximadamente una treintena. La cronología de los restos es muy variada, encontramos ejemplos de época emiral y califal en Córdoba; de cronología almorávide y almohade en Valencia,

2. En las siguientes páginas se recogen tres excavaciones, una en Granada y dos en Málaga, en las que se ha planteado la existencia de un edificio islámico interpretado como funduq que continuó utilizándose tras la conquista cristiana como alhóndiga o mesón. 
Denia, Murcia, Almería o Málaga; y posteriormente, casos nazaríes en Granada, Málaga - Loja (Granada). También se han documentado tres casos de edificios que plantean una continuidad de sus estructuras y su funcionalidad desde época islámica a cristiana que son mencionados de forma específica en este artículo más adelante. La información que han proporcionado estas intervenciones ha permitido conocer mejor la variedad de estas estructuras que, con anterioridad, habían sido entendidas según el esquema ofrecido por el al-funduq al-ŷadìd de Granada, uno de los ejemplos más tardíos (TORRES, 1946; ROLDÁN et al., 2020).

Los restos muestran que estos edificios eran de planta cuadrangular y se estructuraban en torno a un patio central con andenes perimetrales desde los que se accedía a los distintos espacios que componían las crujías. El patio podía estar porticado en uno o varios de sus lados. Por ejemplo, el funduq califal de Cercadilla, en Córdoba, presenta porticado el lado norte del patio (CASTRO, 2005), el caso almohade de la calle Corretgeria de Valencia tiene porticados sus lados norte, este y oeste (MARTÍ, BURRIEL, 2008), mientras que encontramos porticados los cuatro lados del patio del edificio almohade de la calle Marqués del Campo de Denia (GISBERT, 2014) y el del al-funduq al-ŷadìd nazarí de Granada (TORRES, 1946). El número de crujías suele ser de cuatro en la mayoría de los casos, aunque en muchos de estos edificios solo han podido documentarse tres de ellas y se ha planteado como hipótesis la existencia de una cuarta (CLAPÉS, 2014-2015; GISBERT, 2007: 230). Estas crujías suelen estar compartimentadas en espacios de dimensiones similares entre sí, como en los edificios del arrabal de poniente, al-Ŷānib al-Garbī, de Córdoba (CLAPÉS, 2014-2015; VÁZQUEZ, 2016: 471; CAMACHO, VALERA, 2020), los edificios de Denia (GISBERT, 2020; GISBERT, 2007: 230; GISBERT, 2003: 76) o el Corral del Carbón de Granada (TORRES, 1946). También encontramos casos en los que alguna de las crujías presenta un salón más amplio sin divisiones internas, generando un espacio singular en el interior del edificio, como en dos de los edificios de la Ronda Oeste de Córdoba (CAMACHO, VALERA, 2020: 131 y 133) o en el de la calle Corretgeria de Valencia (MARTÍ, BURRIEL, 2008). Además, muchos de estos edificios han sido conservados de forma parcial, o los solares de excavación arqueológica delimitaron las zonas del edificio que se pudieron documentar, por lo que no hemos podido conocer con exactitud la disposición interna de las cuatro crujías. De su planta destacamos también que no presenta la disposición tradicional de las viviendas andalusíes en las que las zonas norte y sur constituían los salones principales de la vivienda. Por el contrario, vemos que las crujías este y oeste se extienden hasta los extremos de la estructura, ocupando parte de los espacios considerados como principales, incluso en los fanādiq con una disposición más tradicional, los que mantenían un gran salón en una de las crujías.

Con respecto a sus dimensiones, se trataba de edificios de gran envergadura, todos los casos en los que se ha podido documentar el edificio completo superan los $200 \mathrm{~m}^{2}$, pues la superficie de muchos de estos restos solo ha sido documentada parcialmente y no se ha podido conocer con exactitud en todos ellos. La planta de mayor superficie es la del Corral del Carbón con 830 m² $^{2}$.

El edificio contaría con una única entrada, ofreciendo así una mayor seguridad a sus usuarios y las mercancías que se almacenaran en él. En el edificio se accedería directamente al patio, bien de forma directa o con un recorrido en recodo. El acceso lo encontramos en la parte central de uno de los lados del edificio, generalmente en el ubicado en una calle principal. Algunos de estos ejemplos los encontramos en Córdoba (CASAL, 2020: 237; CAMACHO, VALERA, 2020), Denia (GISBERT, 2014), y Granada (TORRES, 1946). También se han documentado accesos desde un adarve o desde uno de los laterales del edificio y no desde su fachada principal (CLAPÉS, 2014-2015: 244; CARA et al., 2000: 172). En cuanto a la apariencia y monumentalidad de los accesos destaca la portada del Corral del Carbón en Granada, aunque se ha considerado como algo excepcional por 
la propiedad regia de este edificio, primero en manos de las esposas del sultán y posteriormente como propiedad de los Reyes Católicos (ORIHUELA, 1995: 205). Otros accesos más modestos pero destacables por sus diferencias con respecto a las edificaciones de su entorno los encontramos en Córdoba, uno en el vano geminado que daba acceso a uno de los fanādiq identificados en el arrabal de poniente (CAMACHO, VALERA, 2020: 132) y otro en el acceso del funduq del arrabal de Šaqunda, más ancho que las edificaciones de su entorno y con materiales de reaprovechamiento: piedras de mina como quicialera y dintel de la puerta y sillares de calcarenita como jambas (CASAL, 2020: 237; CASAL et al., 2006: 352). También se ha mencionado una puerta monumental en el inmueble interpretado como funduq en la calle Pedro Jover y calle Chafarinas de Almería (CARA, MORALES, 2006: 42).

En algunos de estos edificios ha sido posible identificar un sistema de evacuación hidráulica complejo, con varios canales de desagüe, que evacúa tanto letrinas como otras zonas del edificio, así como la presencia de puntos de agua con pozos, fuentes o piletas. En el arrabal de Šaqunda de Córdoba solo se han documentado conducciones de agua en relación con el edificio interpretado como funduq (CASAL etal., 2006: 352), por lo tanto, su presencia en estos edificios se presenta como una característica fundamental. Asociada al sistema hidráulico, la letrina sería un espacio esencial en estos edificios. Las encontramos ubicadas en una crujía anexa a una de las calles que rodean el edificio facilitando así la evacuación con atarjeas de corto recorrido. En cuando a su ubicación en el interior del edificio suelen localizarse en uno de los extremos (CASAL, 2020: 241; GISBERT, 2003: 76) o junto al zaguán de acceso (CAMACHO, VALERA, 2020: 130-133). Incluso se ha localizado una letrina en el exterior del funduq de la manzana 14 del arrabal de poniente de Córdoba, pero asociada a este, pues se hallaba en el interior del tramo de adarve privado que conectaba la calle con el acceso al edificio (CLAPÉS, 2014-2015: 245). También se ha propuesto la existencia de letrinas en el piso superior en el caso de la calle Corretgeria de
Valencia al documentarse atanores en bajante en el interior de los muros que conectaban con el sistema de canalizaciones de la planta baja del edificio (MARTÍ, BURRIEL, 2008: 57). Otro aspecto importante del sistema hidráulico sería la presencia de un pozo, una fuente o pileta del que los usuarios pudieran servirse. Se han documentado pozos en la zona central del patio en edificios de Córdoba (CLAPÉS, 2014-2015: 238; CAMACHO, VALERA, 2020: 130133), Denia (GISBERT, 2020) y Loja (BUENDÍA, ÁLVAREZ, 2010: 1344); en la parte septentrional del patio en Valencia (MARTÍ y BURRIEL, 2008: 56) y Almería (CARA et al., 2000: 173); y en el interior de estancias en los edificios de Málaga (ÎNIGUEZ, 2010: 3406; SALADO, ALTAMIRANO, 2011: 39).

Precisamente, ha sido la existencia de canales de evacuación encastrados en los muros, la presencia de una zona porticada en el patio y la robustez de los muros, las características a partir de las cuales se ha propuesto que estos edificios tuvieran más de una planta, aunque no era una condición indispensable. Solo se han conservado dos plantas superiores en el Corral del Carbón de Granada y las escaleras que daban acceso a ellas en la parte central de las crujías laterales (TORRES, 1946: 464).

En cuanto a la funcionalidad de los espacios interiores, tradicionalmente se ha hablado de zonas de servicio, almacén y cuadras en la planta baja, y espacios de alojamiento en la planta alta. En los edificios que no tuvieran pisos altos todos estos espacios se encontrarían repartidos en las distintas crujías. Sin embargo, esta identificación no ha podido ser precisada desde la arqueología con total garantía. Se han documentado estructuras de combustión y se ha planteado como hipótesis que alguna de las estancias de estos edificios fuera zona de almacén por haber hallado acumulaciones de restos cerámicos de su interior (CARA, MORALES, 2006: 39) o estructuras que podrían servir para almacenamiento, como las piletas cuadrangulares de ladrillo documentadas en el funduq de la Puerta del Mar de Málaga (SALADO, ALTAMIRANO, 2011: 35-37). Sin embargo, de los tipos cerámicos 
hallados en estas excavaciones se han documentado generalmente en proporciones similares materiales vinculados a servicio de mesa, cocina y almacenamiento, por lo que no ha podido establecerse a partir de ellos un uso concreto de las estancias llevándonos a proponer su polifuncionalidad (por ejemplo, en Málaga, î̃̃IGUEZ, 2010: 3413). Con respecto a las estructuras de combustión, en su interpretación no se ha planteado un uso específico, culinario o artesanal, por lo tanto, sin poder descartar ninguna de las opciones, de nuevo nos encontraríamos ante espacios polifuncionales (BUENDÍA, ÁLVAREZ, 2010: 1345). Se ha propuesto también que grupos de artesanos o comerciantes podrían agruparse en estos edificios en función de los productos con los que trabajaban y usar sus espacios como taller (CHALMETA, 2010: 302-304).

En estos edificios también debería de haber un espacio reservado para la persona que lo administraba que viviría en él con su familia. J. A. Gisbert (2014) propone que este espacio se ubicara en uno de los laterales del corredor de acceso al edificio y L. Torres (1946: 465) lo ubica en la planta superior sobre la entrada en el Corral del Carbón de Granada, desde el que vigilar la entrada, el patio y el interior del edificio.

Lo habitual sería que los comerciantes y sus mercancías llegaran a las ciudades a lomos de animales, pero por el momento no se han identificado establos en el interior de estos edificios en al-Andalus, por lo que planteamos que estos animales permanecieran en otros espacios habilitados para ello en la medina, fuera de los fanādiq. Solo en el caso del edificio del Llano de la Torroba en Rincón de la Victoria (Málaga) se ha planteado que en una de las fases de uso un tramo de la calle en dirección norte-sur que circundaba uno de los lados del funduq podría haberse cerrado y haber sido utilizado como caballerizas (FLORIDO, 2010: 3307).

La ubicación de los fanādiq en el entramado urbano está relacionada con la actividad y el trasiego de personas y bienes, junto a otras zonas comerciales de las ciudades islámicas como el zoco o la alcaicería cuyo núcleo principal estaría en el entorno de la mezquita aljama (CASAL, 2020: 246; CHALMETA, 2010: 334; NAVARRO, JIMÉNEZ, 1994: 174). Los encontramos cerca de mezquitas, baños, tiendas o puertas de la ciudad, es decir, en zonas transitadas o cerca de alguna calle principal, tanto en el interior de la medina como en los arrabales.

Ante la hipótesis de que los edificios de tres de estas excavaciones, la de la alhóndiga Zaida de Granada, la del edificio en la calle Sebastián Souvirón de Málaga y la de la alhóndiga de la Puerta del Mar de Málaga, funcionaran como funduq en época islámica y se mantuvieran en uso a lo largo del tiempo hasta convertirse en alhóndiga o mesón tras la conquista de las ciudades, consideramos conveniente exponer los resultados concretos de estas intervenciones. En Granada, bajo los restos de la alhóndiga Zaida de época moderna se documentaron restos de otro edificio cuya cronología se extendía de época almohade a nazarí interpretado como funduq islámico. De época islámica se han documentado algunas estructuras que podrían configurar los muros perimetrales de la crujía sur del edificio, cuya orientación se ha propuesto que responda a la ubicación de una canalización o acequia andalusí que discurría paralela a las estructuras documentadas, al sur. Dichas estructuras han sido interpretadas como cimentación de los muros de ladrillo de la construcción moderna. Al norte de los muros se identificaron niveles islámicos bajo los pavimentos de empedrado del patio de la alhóndiga Zaida moderna que han sido interpretados como niveles del patio del funduq (ARROYO et al., 1995). Sin embargo, las construcciones modernas y contemporáneas en el solar y el propio límite del solar de excavación, no permitieron documentar más partes del edificio islámico precedente para entender su funcionamiento en época andalusí e identificar los cambios que se produjeron en el edificio al pasar de manos islámicas a cristianas.

En Málaga, el edificio hallado en la manzana que forman las calles Sebastián Souvirón, Olózaga y Marqués fue interpretado como un funduq construido en época califal con distintas fases de uso en los siglos posteriores hasta 
época nazarí. Ante la presencia de material cerámico de importación del levante peninsular y de Génova, C. Íñiguez (2010: 3414) plantea que este funduq podría haber sido uno de los controlados por los genoveses en la ciudad de Málaga en época nazarí, en la que se ha documentado su presencia e instalación en el Castil de Genoveses (PERAL, íNIGUEZ, 2016). En cuanto al uso del edificio también en época cristiana, por la mención en el libro del Repartimiento de un mesón donde se ubica este solar se ha planteado que la funcionalidad del edificio como alojamiento se mantuviera tras la conquista de la ciudad (íNIGGEZ, 2010: 3414). Del edificio se documentaron dos crujías paralelas formadas por espacios rectangulares y cuadrangulares con una infraestructura de saneamiento compuesta por varias atarjeas, pozos negros y pozos de agua potable resultado de las reformas que se produjeron en el edificio durante sus distintas fases de uso (î̃̃lGUEZ, 2010: 3405). Algunas de estas estructuras hidráulicas se mantuvieron en uso desde el momento de su construcción mientras que otras fueron utilizadas durante alguna de las fases y posteriormente colmatadas. Sin embargo, la ausencia de patio central en este edificio supone la principal diferencia con el resto de edificios que recogemos en este artículo. Teniendo en cuenta sus características, dimensiones y su ubicación en la ciudad de Málaga, en el entorno de otros edificios artesanales y comerciales y próximo a la Puerta del Mar, pese a la ausencia de paralelos tipológicos, la arqueóloga ha planteado que se tratara de un funduq utilizado principalmente como alojamiento (Î̃NIGUEZ, 2010: 3407).

Por último, la excavación realizada en la Plaza Félix Sáenz de Málaga permitió documentar parte de la alhóndiga moderna y, bajo ella, los restos de un edificio interpretado como funduq construido en época califal-taifa. Del funduq islámico se documentó parcialmente la zona sur del inmueble, en el que se identificaron cinco estancias interiores de la crujía sur (SALADO, ALTAMIRANO, 2011: 33-35). La presencia de estructuras interpretadas como zona de almacén de época nazarí permitió proponer un uso continuado del edificio hasta su reforma en época moderna. Con respecto a su sistema hidráulico se documentó un pozo circular en el interior de una de las estancias, y pozos y atarjeas en el exterior del edificio y adosados a este (SALADO, ALTAMIRANO, 2011: 39-43).

\section{URBANISMO DE MADĪNAT MURSIYA}

Dada la relación entre los fanādiq y su ubicación en el entramado urbano de una ciudad, consideramos necesario realizar una breve contextualización de los ejes viales de la ciudad de Murcia para, posteriormente, poner en relación los restos arqueológicos interpretados como funduq con el espacio que ocupaban en el interior de la medina. En Murcia se ha identificado un entramado viario andalusí jerarquizado que conectaba las principales puertas de la ciudad. Esas puertas fueron los puntos naturales de entrada del comercio y aglutinarían en su entorno las instituciones e infraestructuras necesarias para el almacenamiento de productos, alojamiento de comerciantes y pago de impuestos, así como de otros servicios como baños (NAVARRO, JIMÉNEZ, 1994: 174).

El eje vial principal se encontraba al sur de la ciudad y la recorría de este a oeste. Unía la Puerta de Orihuela, en el extremo oriental, con la Puerta de Vidrieros, en el occidental. El recorrido conectaba en su parte central con la Puerta del Puente. Se corresponde con las actuales calles de San Antonio, calle Frenería y calle San Pedro. Esta vía se bifurcaba hacia el noroeste desde la actual calle San Pedro, recorriendo la calle San Nicolás hasta desembocar en la puerta del Zoco (NAVARRO, JIMÉNEZ, 1994: 172-173). Esta vía ha sido interpretada como zoco "lineal" en la que se ubicarían tiendas a ambos lados de la calle.

La ciudad contaba hacia el norte con otros dos ejes viales que, siguiendo la disposición de la arteria principal, la recorrían en dirección este-oeste. Uno era el que se correspondía con las actuales calles Selgas, San Cristóbal, San Lorenzo y Platería. Extramuros de la medina al norte, en el arrabal de la Arrixaca, encontramos el tercero de estos ejes viales que discurría 
siguiendo el trazado de la acequia Aljufía y conectaba la puerta del Mercado al este con la puerta de la Noguera al oeste. Se corresponde con las actuales calles Acisclo Díaz, Maestro Alonso, Santa Clara y Enrique Villar (NAVARRO, JIMÉNEZ, 1994: 173). La mención en las fuentes a este eje ha sido traducida como "Camino Alto de la Huerta" o "Calle Principal (o mayor) de la Huerta" (JIMÉNEZ, 2013: 698). El urbanismo en el arrabal de la Arrixaca, documentado principalmente en el conjunto arqueológico de San Esteban, presenta una red viaria jerarquizada en la que se han identificado calles principales, secundarias y adarves. La denominada calle $\tilde{N}$ del conjunto arqueológico de San Esteban, con orientación este-oeste, puede ser interpretada como un eje vial en el arrabal extramuros que daría continuidad a los tres ejes viales que recorren de este a oeste la medina (ROBLES, SÁNCHEZ, NAVARRO, 2011: 208).

Estas tres vías principales eran atravesadas en dirección norte-sur por otros tres ejes viales. Al este se encontraba el trazado que se corresponde con las actuales calles Saavedra Fajardo y Rambla. Al oeste, otro eje sería el que ha pervivido en las actuales calles Pascual y Santa Isabel, calles que aglutinaban en su entorno el comercio (ROSELLÓ, CANO, 1975: 25). Entre ambas vías encontramos el eje vial que conectaba la puerta de Santo Domingo con el entorno de la mezquita aljama y las puertas del Sol y del Puente, que se corresponde con las actuales calles Jabonerías y Sociedad (JIMÉNEZ, 2013: 705).

El resto del entramado viario de la ciudad de Murcia lo componían calles que partían de las vías principales, según su relevancia: calles mayores de barrio, calles públicas menores, callejones o adarves (NAVARRO, JIMÉNEZ: 1994: 175).

\section{FANĀDIQ EN MURCIA: EDIFICIOS COMPLETOS COMO CASOS DE ESTUDIO ARQUEOLÓGICO}

En la ciudad de Murcia los restos de seis inmuebles han sido propuestos como posible funduq o alhóndiga de entre varias hipótesis que plantean que se trate de edificios públicos y/o de uso comercial. Cinco de estos edificios se encontraban en el interior de la medina: el edificio de la Plaza Belluga, los restos en la calle Pascual y calle Conde Valle de San Juan, los restos de la calle Montijo, los restos de la Plaza de Santa Eulalia y los de la calle Granero. Solo se ha documentado uno de estos edificios en el conjunto arqueológico de San Esteban, en el que se ha documentado una parte de la zona norte del arrabal de la Arrixaca, principal arrabal islámico extramuros de la ciudad de Murcia. Además, en el presente artículo se incluye una propuesta de reinterpretación del edificio identificado como "Espacio 4" en la excavación Garaje Villar de Murcia, ubicado en el interior de la medina. Este último caso eleva a siete el número de posibles fanādiq en Madinat Mursiya (Figura 1).

Uno de los problemas añadidos a la interpretación de estos edificios es su documentación parcial en excavaciones dentro del casco urbano de las ciudades andalusíes. El caso de Murcia no es una excepción, solo en tres de estas excavaciones, en la de la Plaza Belluga, en el conjunto arqueológico de San Esteban y en la excavación de Garaje Villar, se ha podido documentar el edificio completo (Figura 2). El resto de intervenciones, debido a los límites de los solares excavados, ha sacado a la luz los restos de estas estructuras de forma parcial, pudiendo documentar solo una o varias crujías del edificio, sin que haya sido posible conocer la planta completa de estos inmuebles (Figura 3). A continuación, se analizará con detalle cada uno de estos posibles fanādiq partiendo de los casos de estudio en los que se ha conservado el edificio completo.

El edificio de la Plaza Belluga fue excavado entre los años 1993 y 1995 en la parte oriental de un solar delimitado por la calle Frenería al norte, la calle San Patricio al sur y la Plaza Belluga al este. En el solar, además del edificio interpretado como alhóndiga por los arqueólogos, se identificaron cuatro viviendas y cuatro tiendas (Figura 4). La zona del solar donde se ubicaba el edificio planteaba una mayor complejidad para su interpretación puesto que 


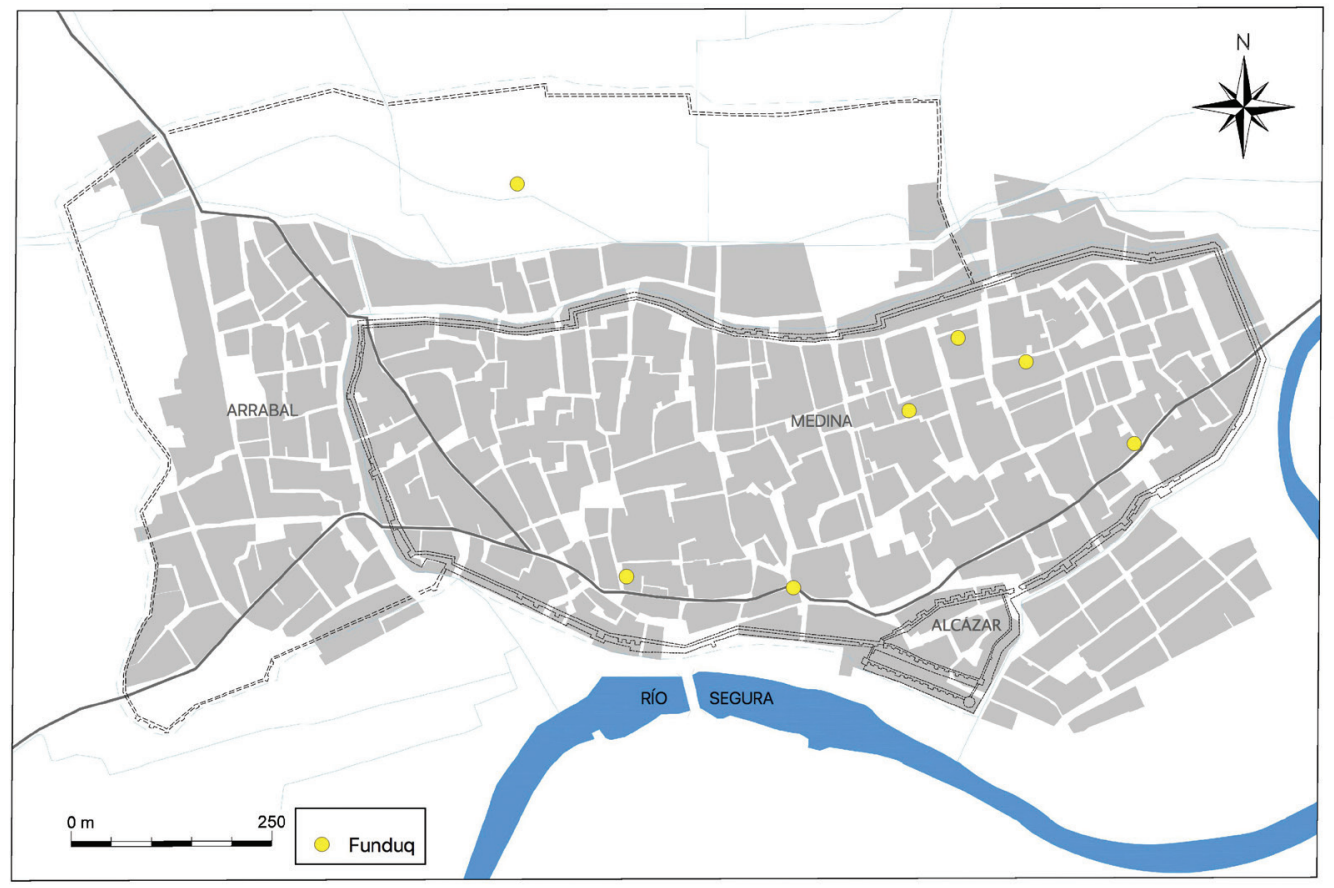

Fig. 1. Plano de ubicación de posibles fanādiq en Murcia. Con una línea continua aparecen señaladas las calles principales de la ciudad (Elaboración propia sobre el plano base de José Gabriel Gómez Carrasco).

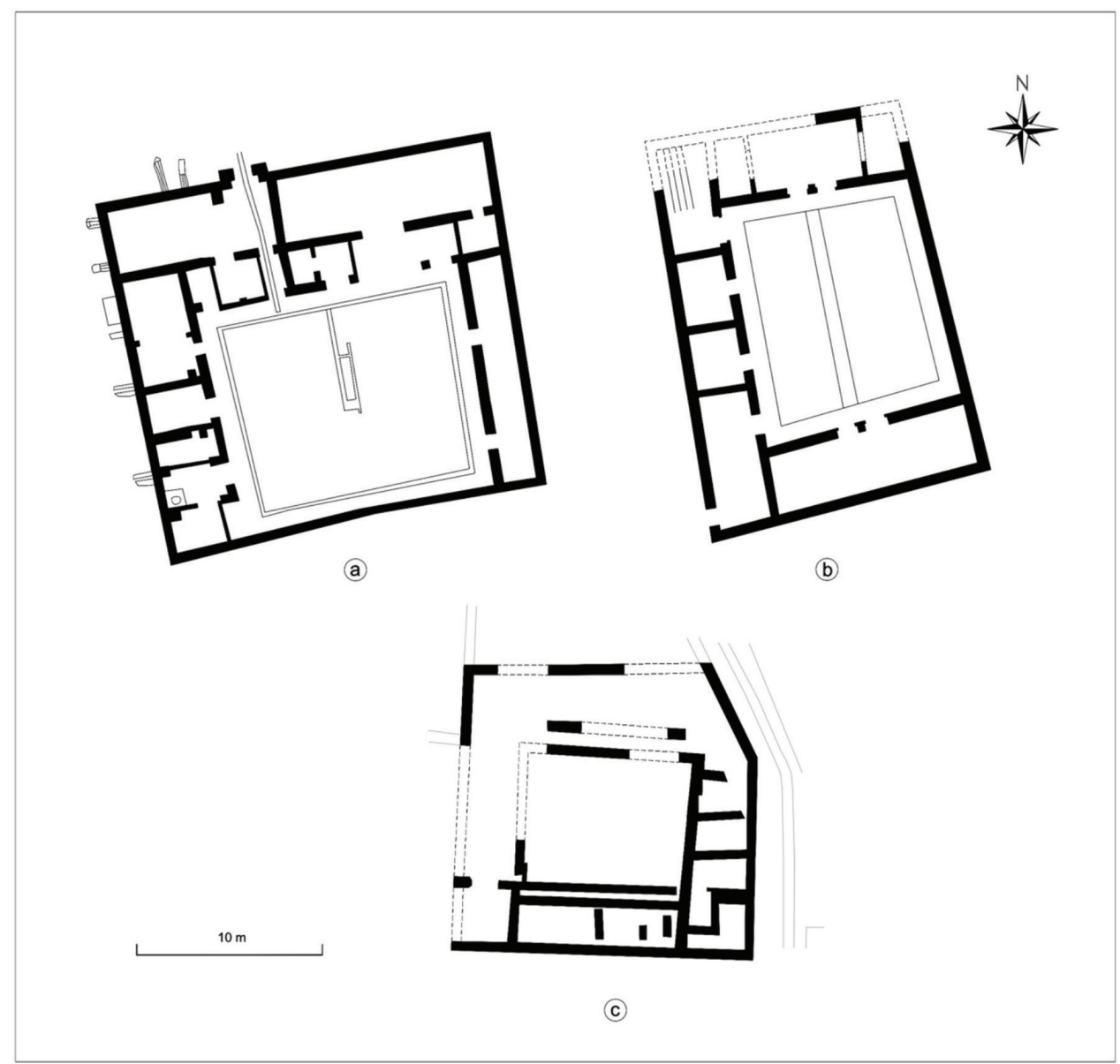

Fig. 2. Plantas de edificios completos documentados en Murcia. A: conjunto arqueológico de San Esteban, B: Garaje Villar, C: Plaza Belluga (Elaborado por José Gabriel Gómez Carrasco). 


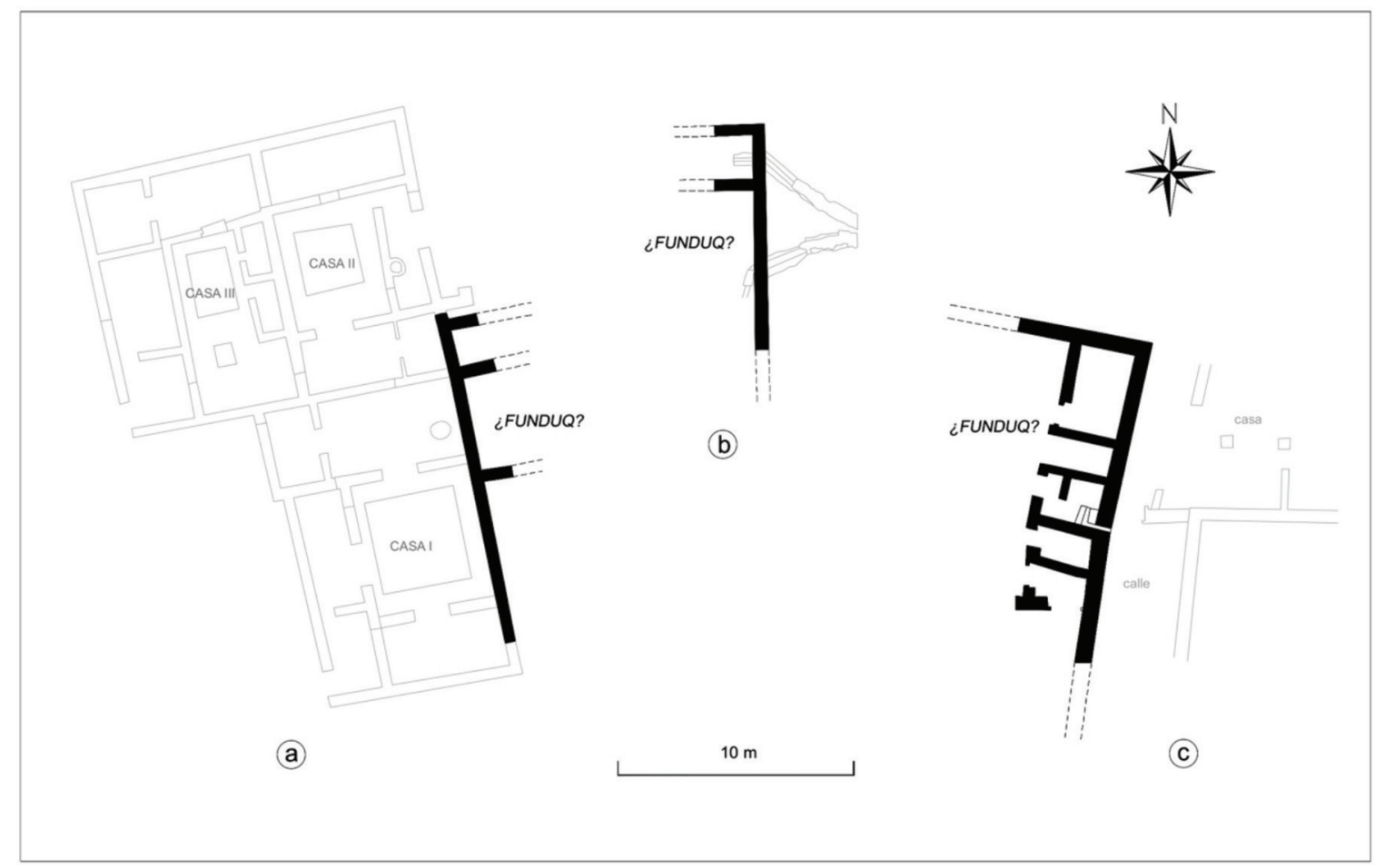

Fig. 3. Plantas parciales de edificios documentados en Murcia. A: calle Granero, B: calle Montijo, C: Plaza de Santa Eulalia (Elaborado por José Gabriel Gómez Carrasco).

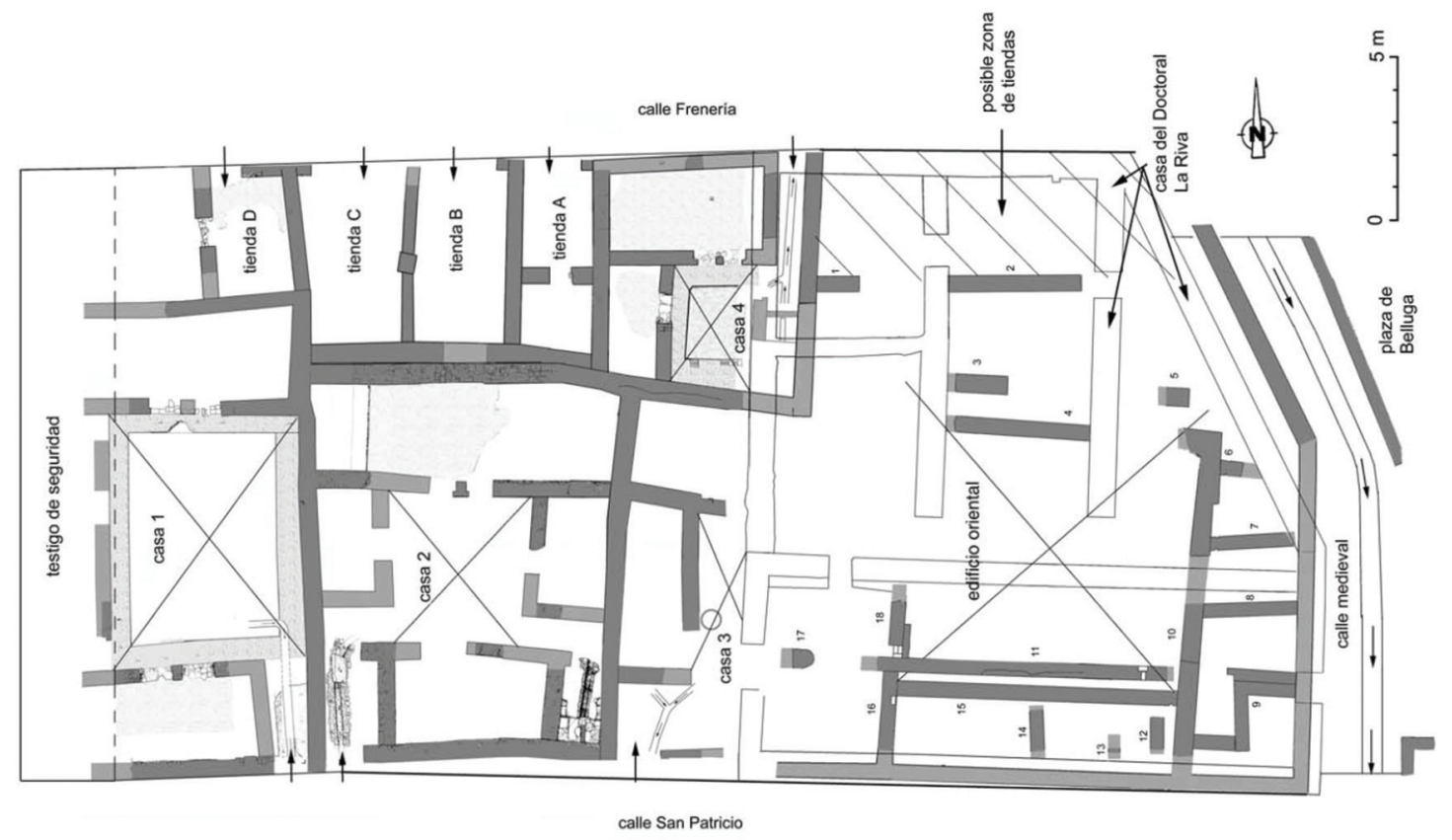

Fig. 4. Plano general de los restos hallados en el solar de la Plaza Belluga (NAVARRO, JIMÉNEZ, 2002: 494).

las estructuras se vieron afectadas por una construcción más moderna, la casa del Doctoral de la Riva del siglo XVIII - XIX. De época andalusí solo se conservaban las cimentaciones de tapial de hormigón del edificio, fechadas junto con los depósitos estratigráficos entre el siglo XII y el XIII. Los alzados y los pavimentos fueron destruidos para la construcción de la vivienda 
de época moderna. En consecuencia, no se pudieron identificar vanos de acceso en el edificio andalusí que nos permitieran conocer la circulación por su interior (NAVARRO, JIMÉNEZ, 2002: 520-524).

En el edificio se pudieron identificar el patio central y restos de tres de las crujías, siendo la crujía oeste la única de la que no se conservó resto alguno (Figura 5). El patio tenía unas dimensiones de $7 \times 8,5 \mathrm{~m}$. En la zona norte y sur del patio se documentaron dos pares de muros paralelos separados los del norte $0,74 \mathrm{~m}$ y los del sur 0,36 m. Los arqueólogos propusieron que se tratara de las correas de cimentación de pórticos-galerías o andenes, aunque no descartaron que correspondieran a dos momentos constructivos diferentes, sobre todo por el reducido espacio que queda entre los muros al sur (NAVARRO, JIMÉNEZ, 2002: 521).

La crujía norte tenía una disposición rectangular. De ella solo se pudo documentar su anchura de 2,60 m. Al norte de esta, el espacio que se ubica entre el muro de cierre norte y la calle Frenería ha sido propuesto por los arqueólogos como una zona de tiendas abiertas a dicha calle. La crujía sur, también rectangular, medía 8,70 m de longitud. En ella se identificaron estructuras de adobe dispuestas perpendicularmente compartimentando el interior de la crujía. Sin embargo, al no estar relacionadas directamente con el hormigón se ha planteado que pudieran ser anteriores a este. La crujía este se encontraba claramente compartimentada en cuatro espacios con

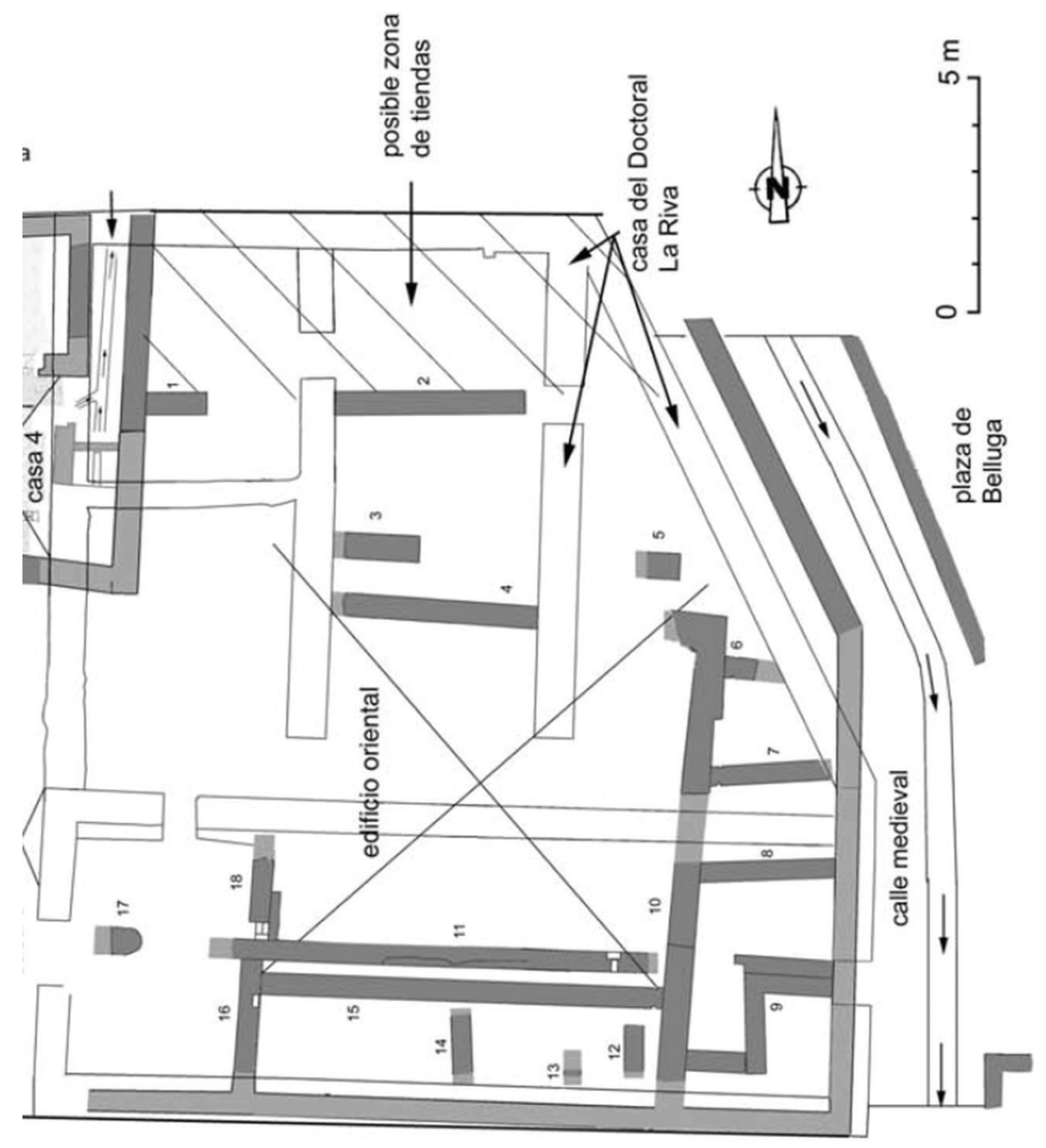

io

Fig. 5. Detalle de la planta del edificio oriental de la Plaza Belluga (NAVARRO, JIMÉNEZ, 2002: 494). 
muros de tapial de hormigón. Dos de estos espacios tenían planta rectangular y otros dos presentaban forma de "L" y fueron identificados como letrinas, aunque no se halló la estructura de evacuación en el interior.

El ángulo noreste del edificio presentaba una planta achaflanada, adaptándose a la disposición de la calle andalusí, de entre 2,20 y 2,50 m de ancho, que discurría por el exterior del lado este del mismo en los siglos previos a la construcción de la plaza en esta zona de la ciudad en el siglo XVIII. Este punto resulta de especial interés a la hora de interpretar la funcionalidad del edificio pues en esa parte de la calle se encontraron cinco desagües consecutivos que llevaron a los arqueólogos a plantear la presencia de letrinas también es esa zona, aunque igualmente no se hubieran localizado estructuras en el interior que conectaran con esos canales de evacuación (NAVARRO, JIMÉNEZ, 2002: 523).

Los arqueólogos concluyeron que podría tratarse de una gran casa, una "casa de abluciones" o un edificio público como una alhóndiga (NAVARRO, JIMÉNEZ, 2002: 523). Son varias las características que nos llevan a plantear el uso público de este edificio y a interpretarlo como un funduq andalusí. Por un lado, la disposición interior del mismo, especialmente por la compartimentación en espacios más pequeños de la crujía este y el hecho de que esta llega a ocupar parte del ángulo sureste que, normalmente, en una vivienda andalusí de grandes dimensiones es ocupado por la crujía sur. Las crujías norte y sur solían ser las más amplias y principales de una vivienda y, en ellas, el salón sur y norte se extendían hasta los extremos laterales. Por otro lado, encontramos en la crujía este los espacios en "L" interpretados como letrinas, así como los cinco desagües en la calle en relación con el ángulo noreste del edificio, configurando así un complejo sistema hidráulico de evacuación de aguas. Sin embargo, la ausencia de estructuras en el interior del edificio no ha permitido concretar la funcionalidad de estos desagües. Por lo tanto, no podemos descartar ni su uso como parte de letrinas, planteado por sus excavadores, ni que los espacios fueran utilizados para otras actividades que pudieran necesitar de una evacuación directa de aguas, quizás una zona de cocina, un espacio de avituallamiento o un taller o zona de producción artesanal.

Por último, debemos tener en cuenta la localización del edificio. Las tiendas documentadas en el solar fueron interpretadas como parte del zoco lineal que recorría la medina de Murcia a lo largo de la actual calle Frenería. Es decir, encontramos el edificio a espaldas de un tramo de tiendas, junto a uno de los ejes viales principales de la ciudad de Murcia y a escasos metros de la mezquita aljama.

Otro ejemplo de edificio completo lo encontramos en el conjunto arqueológico de San Esteban. Este conjunto fue hallado con las excavaciones que se iniciaron como intervención de urgencia en 2009 y que desde 2018 se han retomado como proyecto de investigación, denominado proyecto Fase $0^{3}$, que ejecuta la Universidad de Murcia en el marco de un Convenio de colaboración con el Ayuntamiento de Murcia. En el conjunto arqueológico de San Esteban se documentó un amplio sector del arrabal de la Arrixaca, principal arrabal extramuros de la ciudad de Murcia en época andalusí. El solar se encuentra delimitado al norte por la calle Jerónimo de Roda, al oeste por el callejón Burruezo, al este por la calle Portillo de San Antonio y al sur por la calle Acisclo Díaz. En este artículo nos centraremos en una de las infraestructuras excavadas, el denominado Recinto I (Figura 6). Ya en 2009 los arqueólogos que dirigieron la intervención plantearon, entre otras hipótesis, que se tratara de un funduq o una alhóndiga (ROBLES, SÁNCHEZ, NAVARRO,

\footnotetext{
3. Proyecto de revisión y diagnóstico del estado de conservación, estudio pluridisciplinar, adopción de medidas de consolidación y exposición temporal en el yacimiento arqueológico de San Esteban (Recinto I, Maqbara, Oratorio y calles adyacentes. Los detalles del proyecto se pueden consultar en la web: http://sanesteban.um.es/
} 


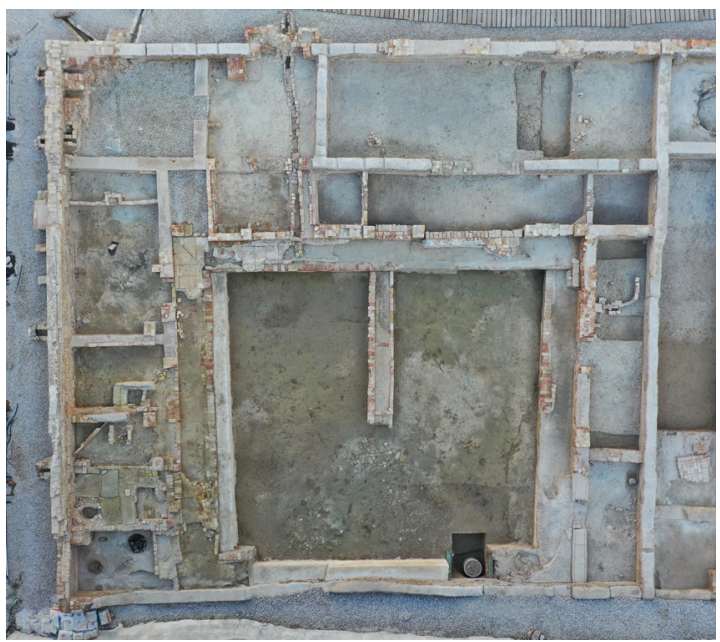

Fig. 6. Fotografía cenital del Recinto / durante el proceso de excavación en 2019 (Recuperado de: https://sanesteban.um.es/imagenes/).

2011: 211). Tras las recientes intervenciones en las que se ha continuado excavando sus depósitos, los arqueólogos que hemos dirigido la intervención hemos reafirmado dicha hipótesis (EIROA et al., 2019: 44-45), aunque los restos y los materiales hallados aún están siendo estudiados cuando escribimos estas páginas.

El Recinto I es un edificio de planta cuadrangular con unas dimensiones de 21,5 x 19 $\mathrm{m}$ de lado y una superficie de $410 \mathrm{~m}^{2}$. El edificio ha sido interpretado como funduq por presentar las características asociadas a este tipo de edificios. Tiene dimensiones mayores a las de una vivienda y se ha planteado que tuviera una planta superior. Su planta se estructura en tres crujías, norte, este y oeste, en torno a un gran patio central. La crujía norte cuenta con dos cuerpos, en la zona sureste de esta crujía se ha documentado una zona porticada, como espacio intermedio que da acceso a la gran sala norte. La crujía oeste es la que presenta una mayor compartimentación en espacios más pequeños y ha sido interpretada como zona de servicio con espacios con un uso polifuncional, en los que hay algunas estructuras de combustión, excepto el ubicado en el extremo noroeste en el que se ha documentado una estructura de ladrillo de letrinas dobles, lo que ha confirmado el uso público y colectivo del edificio. La crujía este presenta dos grandes espacios que abren directamente al patio (EIROA et al., 2019: 44).

Destacamos de este edificio el complejo sistema de atarjeas que se ha documentado, con hasta nueve canalizaciones que desaguan desde las crujías norte y oeste hasta las denominadas calles $\tilde{N}$ y $\mathrm{N}$ respectivamente. La presencia de estas atarjeas también permite distinguirlo de una estructura residencial. El edificio contaba con un único acceso desde la calle $\tilde{N}$, interpretada como uno de los principales ejes viales que atravesaban de este a oeste el arrabal de la Arrixaca. Próximo a este edificio y en la misma calle se documentaron unas tiendas. Las características de la planta de este edificio y su ubicación en el arrabal permiten plantear que se trate de un funduq.

El tercer edificio completo documentado se localizó en la excavación del Garaje Villar, llevada a cabo entre 1987 y 1988, en la que se documentó una manzana de casas andalusíes. El solar estaba delimitado por la calle Selgas al norte, Santa Quiteria al sur, Saavedra Fajardo al oeste y Siervas de Jesús al este (MANZANO, 1995). En concreto, los restos del denominado "Espacio 4", interpretado como una mansión de tipo residencial posiblemente propiedad de un individuo en posición social acomodada, miembro de una clase privilegiada (comerciantes, artesanos, altos funcionarios, aristocracia militar, grandes propietarios, etc.) (MANZANO, 1995: 366), fueron los que llamaron nuestra atención al compararlos con el resto de edificios recogidos en el presente trabajo.

El "Espacio 4" era un edificio de planta rectangular $(14 \times 21 \mathrm{~m})$ y $300 \mathrm{~m}^{2}$ de superficie. En él se documentaron tres fases de uso siendo, de la más antigua a la más moderna, el nivel I superior asociado al siglo XI, el nivel II inferior asociado al siglo XII y el nivel II superior asociado al siglo XIII. El nivel mejor documentado fue el nivel II, mientras que las estructuras aparecidas asociadas al nivel I fueron escasas y parciales (MANZANO, 1995: 258). 
El acceso al edificio se realizaba por el extremo suroeste, al que se llegaba a través de un estrecho y largo adarve. Durante la fase de uso identificada como nivel II inferior (siglo XII) el edificio contaba con tres crujías: norte, sur y oeste, en torno a un patio central $(10 \times 13 \mathrm{~m})$ con una superficie de $130 \mathrm{~m}^{2}$, compuesto por un arriate con andenes perimetrales de 0,90 m de ancho y un posible andén central que dividía el patio en dos de 0,80 m de ancho (Figura 7) (MANZANO, 1995: 369). La crujía norte albergaba una gran sala $(10 \times 3,10 \mathrm{~m})$ con la disposición tradicional de dos alcobas en ambos extremos. La crujía sur presentaba una sala similar a la de la crujía norte, aunque en ella no se pudo documentar la existencia de alcobas laterales.

La crujía oeste estaba compartimentada en cuatro espacios diferentes, con una anchura aproximada de 2,50 m. Los dos espacios centrales tenían unas dimensiones similares de entre 3 y 3,50 m de longitud a los que se accedía a través de vanos simples desde el patio y a los que no se le adscribió ninguna funcionalidad concreta. A través del espacio sur de la crujía oeste se accedía al edificio marcando un recorrido en recodo. Además de como zaguán, este espacio se interpretó como cocina por el nivel de uso que presentaba con tierra apisonada endurecida y quemada, funcionalidad que mantuvo en la siguiente fase de uso. El espacio norte de esta crujía $(2,50 \times 6 \mathrm{~m})$ fue interpretado como letrina por la presencia de una atarjea de mortero de cal que desaguaba hacia el norte, hacia la calle Selgas. A él se accedía desde el patio a través de un vano de 1,50 m de ancho. También se documentó junto al muro sur de este espacio un gran alcadafe embutido en el suelo y un tubo cerámico de

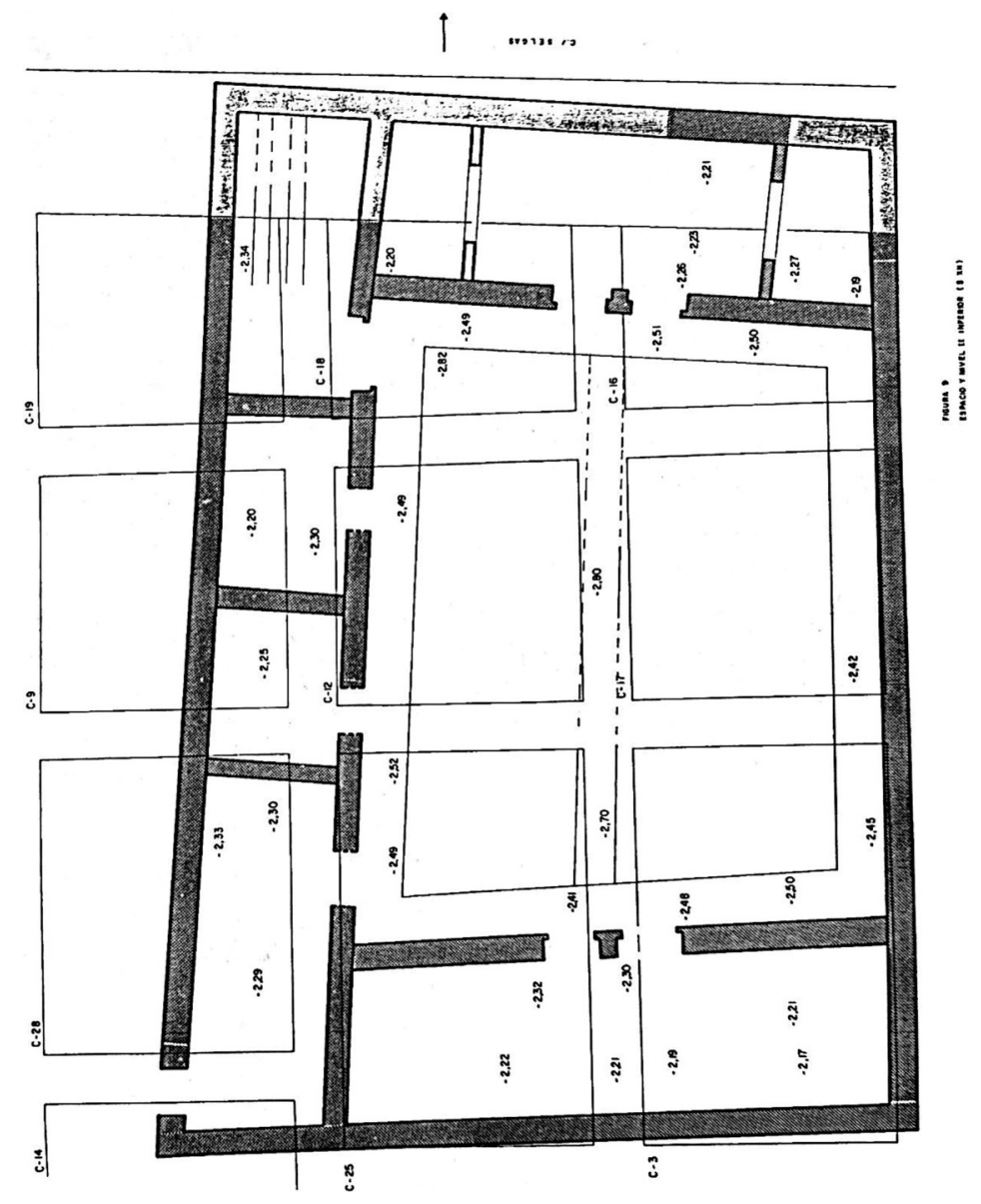

Fig. 7. Planta de los restos del nivel II inferior (siglo XII) del "Espacio 4" de la excavación Garaje Villar (Manzano, 1995: 369). 
0,25 m de diámetro que presentaba una pendiente similar a la atarjea y también desaguaba hacia el norte atravesando el muro de cierre norte del inmueble (MANZANO, 1995: 370).

Durante la fase de uso identificada como nivel II superior (siglo XIII), el inmueble mantuvo las mismas dimensiones que en la fase anterior, pero se produjeron remodelaciones en su interior (Figura 8). Contó entonces con cuatro crujías, creando una mayor simetría entre ellas con la construcción de una crujía este de menores dimensiones que el resto (8 $\times 1,20 \mathrm{~m}$ ). A la crujía este se accedía a través de dos vanos simples de $1 \mathrm{~m}$ de ancho. Tenía una disposición tradicional dividida en un espacio central y dos alcobas, en la alcoba sur se ubicaba la escalera de acceso a la planta superior.

En esta fase la crujía oeste redujo sus espacios interiores pasando de cuatro a tres. En el espacio sur, zaguán de acceso y cocina, se añadieron atajos que marcaban una separación entre la que fue propiamente la zona de paso hacia el patio y zona de cocina, que ocupó las partes central y norte de dicho espacio, con unas dimensiones aproximadas de 2,50 $\mathrm{x}$ 2,70 m cada una. En la cocina se documentó una estructura cuadrangular de ladrillo en el extremo noreste "de difícil interpretación"yuna canalización de 0,20 m de ancho que atravesaba el muro de cierre este de la estancia y desaguaba hacia el patio. El espacio central de la crujía oeste lo ocupaba una estancia rectangular de 7,40 m de longitud a la que se accedía desde el patio por un vano geminado de $2,80 \mathrm{~m}$ de ancho. El espacio norte de la crujía estaba muy arrasado, pero en él pudo documentarse una atarjea de desagüe hacia el norte, hacia la calle Selgas, y una pequeña estructura de ladrillo con fondo de lajas de pizarra interpretada como letrina de la vivienda. La anchura

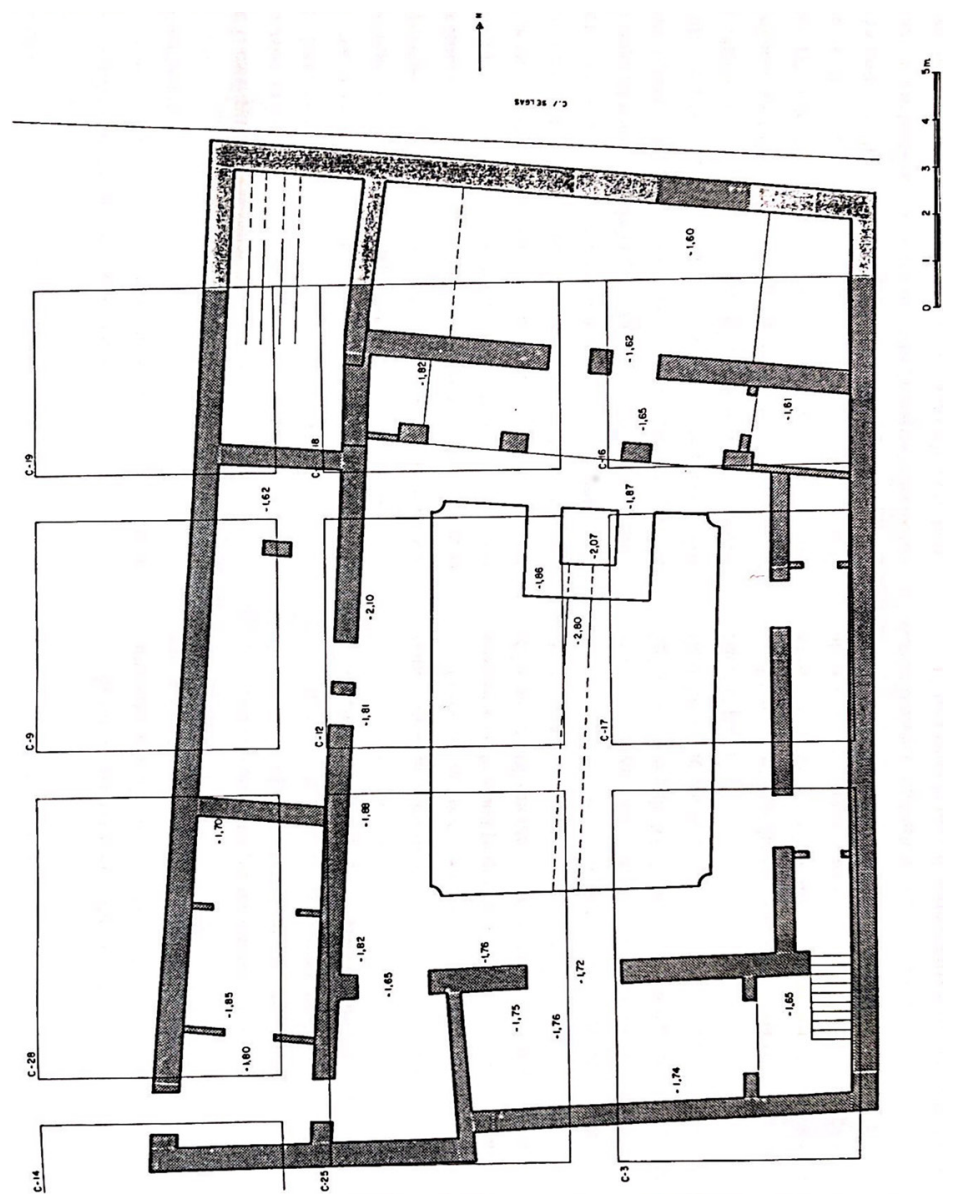

Fig. 8. Planta de los restos del nivel II superior (siglo XIII) del "Espacio 4" (MANZANO, 1995: 367). 
media de la crujía oeste en esta fase era de 2,60 m y fue interpretada en su totalidad como crujía de servicio con dependencias de carácter secundario.

El patio redujo sus dimensiones por la construcción de una zona porticada al norte y de una crujía al este. Formaba un espacio cuadrangular en cuya zona central se localizaba un arriate de $8 \times 6 \mathrm{~m}$, rehundido 0,75 m con respecto a los andenes perimetrales, de entre 1 y $1,5 \mathrm{~m}$ de anchura, y atravesado por un posible andén central al igual que en la fase anterior. Los andenes estaban pavimentados en ladrillo y en los cuatro ángulos que formaba el arriate se localizaron reposaderos o maceteros de forma circular (MANZANO, 1995: 366). En la parte norte del patio se ubicaba una alberca cuadrada construida en tapial de argamasa de 1,20 m de lado y 0,20 $m$ de profundidad, haciendo que el arriate en esa zona adoptara forma de "U", similar al de otras viviendas andalusíes en Murcia en uso durante el siglo XIII (MANZANO, 1995: 367). El patio en esta fase redujo su superficie de 130 $\mathrm{m}^{2}$ a $48 \mathrm{~m}^{2}$ por la construcción de una zona porticada con tres vanos como espacio intermedio entre el patio y la crujía norte a la que daba acceso. La sala norte $(10 \times 3,10 \mathrm{~m})$ mantuvo una disposición tradicional dividida en espacio central y dos alcobas laterales (MANZANO, 1995: 367-368).

A la crujía sur se accedía por un vano de acceso de 1,80 $\mathrm{m}$ de ancho y su interior, al igual que la crujía norte, tenía una disposición tradicional: un espacio central y una alcoba en la parte este. El espacio que debía ocupar la alcoba oeste aparece independiente, como espacio intermedio entre el zaguán y el patio y fue interpretado como vestíbulo (MANZANO, 1995: 368).

Para el arqueólogo, pese a que en el nivel superior de uso se mantuvieron numerosas estructuras del nivel anterior, se debe hablar de dos viviendas diferentes por todas las modificaciones que se realizaron en la última fase de uso (nivel II superior). Las reformas realizadas en el inmueble durante su última fase de uso, como un zaguán de acceso más directo al patio, la construcción de una crujía este y el patio en forma de "U", nos llevan a plantear un uso privado y residencial del edificio durante este periodo, en el que la crujía oeste continuó siendo un espacio polifuncional y de servicio. El característico patio en forma de "U" ha sido documentado en otros espacios domésticos de grandes dimensiones en la ciudad de Murcia, tal y como lo expone Manzano en el artículo.

Sin embargo, algunos elementos nos llevan a plantear en este artículo una reinterpretación del nivel de uso del edificio durante el siglo XII, identificado en la excavación como nivel II inferior, como funduq. En el edificio del siglo XII la crujía oeste, de servicio, se extiende hasta los muros medianeros norte y sur, ocupando los espacios de los extremos que en ámbito doméstico suelen ocupar las crujías norte y sur, al tratarse de los espacios principales de la vivienda. El edificio contaba con un amplio patio en el que se podrían llevar a cabo las diversas actividades que tenían lugar en este tipo de edificios. Además, en esa fase, en el extremo noroeste del edificio se documentaron dos canales distintos de evacuación de aguas, no asociados a ninguna estructura concreta en su interior, que permiten plantear varias hipótesis: que se tratara de un espacio de letrinas colectivas, o bien de una única letrina precedida de otra zona junto al muro sur del espacio en la que se llevara a cabo alguna actividad que necesitara de un punto de evacuación de aguas, o que estemos ante un espacio cuya funcionalidad no podemos precisar pero que haría uso de dos canales de evacuación de aguas. A estas características se añade el hecho de que desde el vano de entrada al edificio el visitante accediera directamente a una posible zona de cocina, convirtiendo al espacio suroeste del edificio en una zona polifuncional como acceso al interior y en la que se llevaban a cabo otra serie de actividades. P. Jiménez (2013: 901) ha planteado este espacio del edificio como el posible establo más 
evidente documentado en el urbanismo de la ciudad de Murcia siguiendo las características de ubicación de los establos según las fuentes históricas: en la misma crujía que se ubica el zaguán o formando parte de él. La presencia de un establo en este edificio sería una característica más que apoyaría la hipótesis de que se tratara de un funduq.

Resulta llamativo en el edificio que el zaguán de acceso en ninguna de las fases de uso del edificio configuró un espacio individualizado, con vanos de acceso descentrados, desde el que acceder al patio preservando la intimidad interior de la vivienda. No estamos ante un espacio intermedio entre el exterior y el interior de la vivienda, sino que desde él se accedía directamente al interior del inmueble y a las actividades que en él se estuvieran llevando a cabo, en este caso en la cocina. Sin embargo, el hecho de que el acceso al edificio se localizara al final de un largo y estrecho adarve que habría que recorrer para llegar a él quizás fue la causa de que no se otorgara una mayor privacidad al zaguán de este edificio.

Una cuestión que quedaría pendiente, en cuanto al sistema hidráulico, sería el canal documentado que evacuaba de la cocina al patio durante el uso del edificio en el siglo XIII. En esa fase se simplificó el sistema de evacuación del edificio y el espacio noroeste quedó como una letrina individual con su respectiva atarjea de desagüe, similar al localizado en otros espacios residenciales.

A estas características estructurales debemos añadir la ubicación en el entramado urbano de este edificio. Lo encontramos en uno de los ejes viales principales de la medina, que la recorría de este a oeste, actualmente fosilizado en las calles Selgas, San Cristóbal y Platería aunque, como se ha mencionado, la puerta principal del edificio se ubicaba en un adarve, no realizándose el acceso desde esta vía principal. En la manzana al norte de este edificio se ubicaba el granero andalusí y a escasos metros al oeste se encontraba una mezquita y un baño.

\section{FANĀDIQ EN MURCIA: EDIFICIOS PAR- CIALMENTE DOCUMENTADOS COMO CASOS DE ESTUDIO ARQUEOLÓGICO}

Una vez recopilados los datos de las excavaciones en las que se documentaron edificios completos y que han sido interpretados como funduq en alguna de sus fases de uso, planteamosa continuación otra serie de restos hallados en la ciudad de Murcia que por su configuración y características no fueron interpretados como una vivienda, sino que se propusieron diversas hipótesis para su interpretación o bien se relacionaron con un uso como edificio público sin precisar su funcionalidad.

En el cruce de la calle Pascual y la calle Conde Valle de San Juan, se llevó a cabo una excavación entre los años 1989 y 1990 en la que se documentaron varías crujías de la zona suroccidental de un edificio y parte de un patio central que fueron interpretados como restos de un edificio público comercial (RUIZ, 1996). Los restos se prolongaban hacia el norte y el este, continuando bajo los edificios de las propiedades contiguas al solar. I. Ruiz (1996: 416 y 418) propone como límites del edificio al norte la calle Madre de Dios y al este un adarve acodado paralelo a la calle Frenería, cerrado en 1893 y conocido como callejón de la Tahona.

Del edificio se documentaron tres fases constructivas, siendo la más antigua la asociada a una estructura previa en el solar. La interpretación planteada por la arqueóloga que dirigió la intervención se ha basado en las estructuras de la última fase constructiva (RUIZ, 1996: 418). Se identificaron cuatro crujías acodadas paralelas, delimitadas por potentes muros de tapial (de entre 0,80 y $0,60 \mathrm{~m}$ de ancho) (Figuras 9 y 10). La crujía exterior estaba compartimentada en ocho espacios yuxtapuestos con unas dimensiones de 4,16 × 2,90 m aproximadamente cada uno, es decir, se documentaron unos $14 \mathrm{~m}$ de longitud de la crujía sur y $14 \mathrm{~m}$ de longitud de la crujía oeste. La segunda crujía se dividía en tres partes desiguales por muros de menor potencia y tenía una anchura de 1,70 m aproximadamente. La tercera crujía aparece sin divisiones 


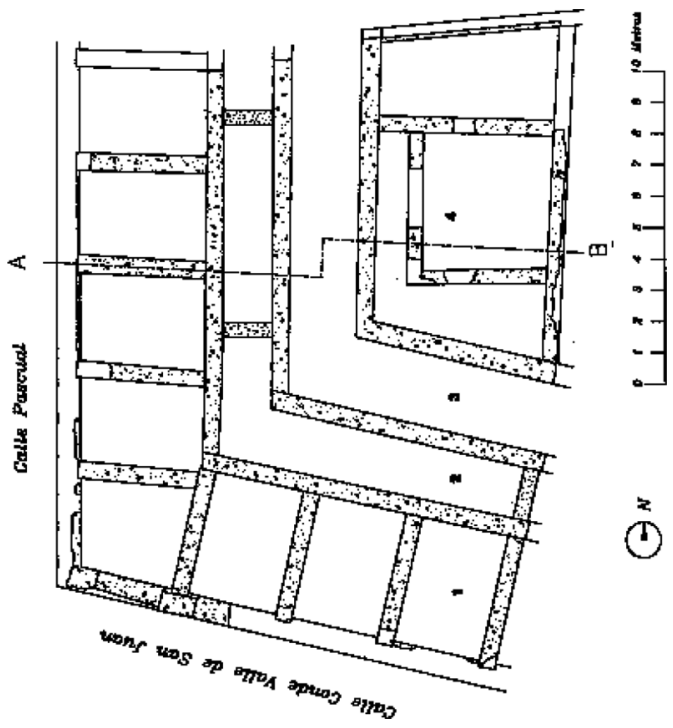

Fig. 9. Planta de los restos documentados en la confluencia de las calles Pascual y Conde Valle de San Juan (RUIZ, 1996: 421).

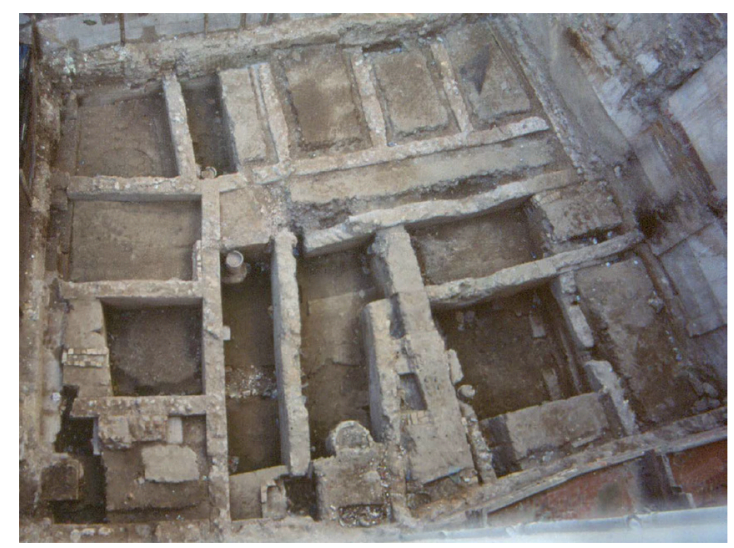

Fig. 10. Fotografía de los restos hallados en la confluencia de las calles Pascual y Conde Valle de San Juan (JIMÉNEZ, 2013: 795).

internas, con una anchura de unos 2,20 m. Por último, la crujía que se encontraba más al interior se subdividía en varios espacios irregulares, con muros de similares características a los del resto del edificio. Paralelo al muro que delimita al sur la tercera crujía se localizó una atarjea con orientación este-oeste, con pendiente hacia la calle Pascual, a la que desaguaría tras introducirse bajo la primera crujía (RUIZ, 1996: 420).

En cuanto a la cronología del edificio, el material cerámico permitió establecer la fecha de fundación del mismo en torno al siglo XI. Para la segunda fase constructiva identificada se estableció un marco cronológico entre los siglos XI y XII asociado a un nivel de pavimento de mortero de cal. La tercera fase constructiva ha sido fechada en el primer tercio del siglo XII (RUIZ, 1996: 420 y 422).

El edificio se ubicaba en unos de los ejes viales principales de la medina de Murcia, en la prolongación hacia el oeste de la actual calle Frenería, en torno a la cual discurriría el zoco en época andalusí y próximo a los baños, ya desaparecidos, de la calle Madre de Dios.

La interpretación y adscripción tipológica de estos restos ha sido discutida. Si bien la arqueóloga en la memoria final de excavación apuntaba a que la falta de comunicación entre las estancias de la primera crujía llevaba a plantear la posibilidad de que se tratara de tiendas individuales de un conjunto mayor, una alcaicería o zoco permanente (RUIZ, 1990), en la publicación realizada sobre esta excavación la autora se decantó por interpretar los restos como parte de un jān o un funduq (RUIZ, 1996, 423-426).

Los arqueólogos J. Navarro y P. Jiménez (1994: 193) propusieron en un trabajo posterior a la intervención arqueológica que este edificio, por su ubicación cerca de la parroquia de San Pedro, fuera la "alfóndega de la sal" que aparece mencionada en el texto de la Quinta Partición (TORRES, 1960: 244). Sin embargo, el hecho de que la calle Frenería en el Repartimiento de la ciudad sea considerada como parte de la collación de Santa María, llevó a I. Ruiz (1996: 425) a cuestionar esta propuesta pues, según V. M. Roselló y G. M. Cano (1975: 75), el Repartimiento mantendría la división previa de la ciudad en época islámica. Por lo tanto, pese a la proximidad del solar a la parroquia de San Pedro, la calle Frenería estaría incluida en la collación de Santa María y no en la de San Pedro.

Posteriormente, P. Jiménez (2013: 795-800) ha planteado la identificación de la tercera crujía con la continuación del adarve que I. 
Ruiz proponía como límite meridional del edificio y, coincidiendo con la arqueóloga en el uso comercial del edificio, ha interpretado los restos como una alcaicería. Actualmente se conserva el tramo inicial del adarve en dirección norte-sur. La coincidencia de la anchura entre el retranqueo que se observa en la zona sur del adarve y la de la tercera crujía es lo que ha llevado a P. Jiménez a proponer que se tratara de la continuación de dicho adarve. En consecuencia, la primera crujía estaría ocupada por tiendas, la segunda crujía sería una galería porticada que a su vez daría acceso a posibles plantas altas, mientras que el espacio identificado como cuarta crujía es considerado por P. Jiménez como parte de otras construcciones que no formarían parte del supuesto patio del edificio. Entre los argumentos que refrendan la hipótesis de la alcaicería encontramos: la cronología de las construcciones, pues todas las tiendas de la manzana fueron construidas contemporáneamente, y la disposición urbana de la manzana en calles paralelas a las principales, creando una retícula interior característica en las alcaicerías (JIMÉNEZ, 2013: 799-800).

Pese a que la compartimentación de la primera crujía y la ubicación en el entramado urbano de la ciudad de Murcia encajarían con las características de un funduq, el hecho de que los únicos vanos de acceso identificados durante la excavación abrieran hacia la calle Frenería desde los espacios de la primera crujía, nos lleva a replantear esta interpretación, dado que un funduq se caracteriza por tener una única entrada para ofrecer una mayor seguridad a las mercancías y huéspedes de su interior. En consecuencia, estamos de acuerdo con la primera hipótesis planteada por la arqueóloga, es decir, que se tratara de tiendas abiertas a la calle Frenería, al igual que las documentadas en otros tramos de esta vía, como en la citada excavación de la Plaza Belluga (NAVARRO, JIMÉNEZ, 2002). Los vanos de acceso identificados se encontraban en la zona suroeste del edificio, en los dos espacios más próximos a la esquina, donde se conservaban parcialmente restos de alzado. La interpretación de los restos de este edificio como tiendas no descarta la hipótesis plateada por P. Jiménez en su tesis doctoral, identificando estos restos como parte de una alcaicería (JIMÉNEZ, 2013: 795-800). Sin embargo, las exiguas evidencias de la circulación en el interior del edificio no permitieron a la arqueóloga contrastar la hipótesis de que todos los espacios rectangulares fueran tiendas abiertas a las actuales calles Pascual y Conde Valle de San Juan, por lo tanto tampoco podemos confirmar la hipótesis planteada por P. Jiménez de que se tratara de una alcaicería, aunque la compartimentación del espacio y la ubicación junto a uno de los ejes viales principales de la ciudad apoyan dicha interpretación.

El siguiente caso lo encontramos en la esquina entre la calle Victorio y la Plaza de Santa Eulalia. En la intervención arqueológica realizada en 2001 se documentó parte de un edificio, en concreto parte de su crujía oriental, del patio y su andén perimetral. También se identificó un adarve de 3,25 m de ancho que delimitaba el edificio por el este (Figura 11) (JIMÉNEZ, 2013: 791-792).

Del patio se excavó una pequeña banda de entre 0,50 y 0,60 m y se documentó el ancho de 0,51 $\mathrm{m}$ del andén solado con sillares de arenisca. La crujía contaba con una longitud aproximada de 13 m y se encontraba compartimentada en seis espacios más pequeños. En la zona central de la crujía se identificó una letrina a la que se accedía por un angosto zaguán acodado y a ambos lados de esta, dos estancias simétricas de 1,30 m de ancho. En los extremos norte y sur de la crujía se ubicaban dos espacios más amplios que ocuparían los ángulos del edificio.

Además de la propia disposición de la crujía oriental del edificio, tres aspectos hacen que sus características difieran en mayor medida de una vivienda andalusí. En primer lugar, ante la presencia de una jamba de sillares de calcarenita en el ángulo noreste se ha propuesto la ausencia de salón norte en el edificio, espacio principal de una vivienda, que se habría visto sustituido por un espacio semiabierto o porticado. En segundo lugar, la orientación 


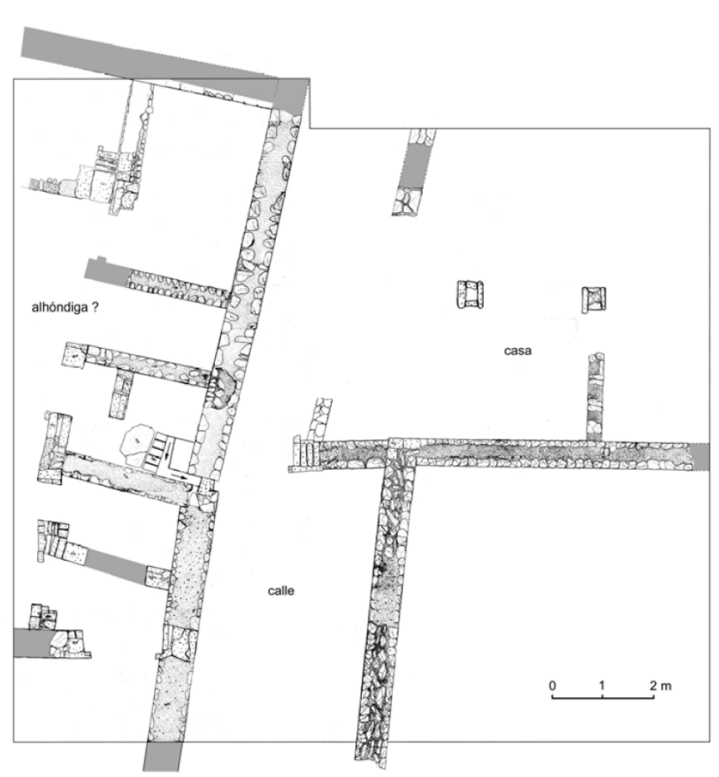

Fig. 11. Planta de los restos hallados en la esquina de la calle Victorio con la Plaza de Santa Eulalia (JIMÉNEZ, 2013: 791).

hacia el sur de las mochetas en el vano de acceso al espacio sur de la crujía oriental plantea que la puerta o puertas de la estancia se cerraran desde el exterior y no desde dentro de la estancia, por lo que se propuso como un posible zaguán de acceso al edificio. Por último, el hecho de que la crujía oriental ocupara las intersecciones con las crujías norte y sur impedía que estas se prolongaran hasta los extremos, igual que en el caso del edificio de la Plaza Belluga. Quedarían así reducidos los espacios considerados como salones principales en una vivienda (JIMÉNEZ, NAVARRO, 2001: 148). Por todas estas características estas estructuras no han sido interpretadas como parte de una vivienda, sino de un espacio público, planteando que se tratara de una posible alhóndiga.

La cronología del edificio ha sido propuesta a partir de la técnica constructiva de las estructuras: zócalos y cimentación con hiladas de mampostería y alzados de tierra, así como jambas y pilares de sillarejo. En consecuencia, el edificio ha sido adscrito a una cronología califal, proponiendo su construcción en el siglo $X$ u XI y su última fase de uso en la segunda mitad del siglo XI. La ausencia de depósito de la memoria final de excavación, así como de una publicación de los resultados de esta excavación y los materiales hallados impiden precisar esta cuestión.

En definitiva, son varias las características que permiten plantear el uso de este edificio como funduq. Por un lado, la estructuración de la crujía oriental del edificio y su prolongación hasta los extremos reduciendo las dimensiones de las crujías norte y sur que posiblemente se ubicarían en ellos. También la presencia de al menos una letrina, por tratarse de uno de los elementos esenciales en este tipo de edificios públicos. Así como la posible ausencia de salón norte y el cierre de una de las estancias desde el exterior, lo que permite plantear que se tratara del punto de acceso al edificio desde el extremo sureste o bien de un espacio de almacenamiento de mercancías u objetos. Los límites del solar no permitieron realizar la excavación de la crujía sur por lo que solamente podemos plantear estas interpretaciones como hipótesis. A las características de la estructura se añade la ubicación del edificio en uno de los ejes viales principales de la ciudad, en la prolongación hacia el este de la calle Frenería, interpretada como zoco lineal de la ciudad. Además, se encontraba próximo a la puerta de Santa Eulalia, en el tramo sureste de la muralla que rodeaba la medina de Murcia, y al baño hallado en el actual número 19 de la calle San Antonio.

Otro caso son los restos hallados en una de las cuadrículas excavadas al sur del solar de la calle Montijo $n^{0}$ 8, entre los años 1988 y 1989. En ella se identificaron dos salas de un edificio que no se adscribió a ninguna tipología (Figuras 12 y 13), ante las dificultades para su interpretación, su continuación bajo el edificio adyacente hacia el oeste y la imposibilidad de documentar el edificio hacia el sur dado que el solar contiguo a la excavación estaba desfondado (BERNAL, JIMÉNEZ, 1993).

Se documentaron 9,5 m de longitud de parte de la crujía oriental, construida en tapial y compartimentada por un muro de mampostería en dos salas, siendo la sala más al norte una letrina, construida en mortero de cal con una abertura rectangular estrecha y la otra de una funcionalidad indeterminada. Las dos salas 


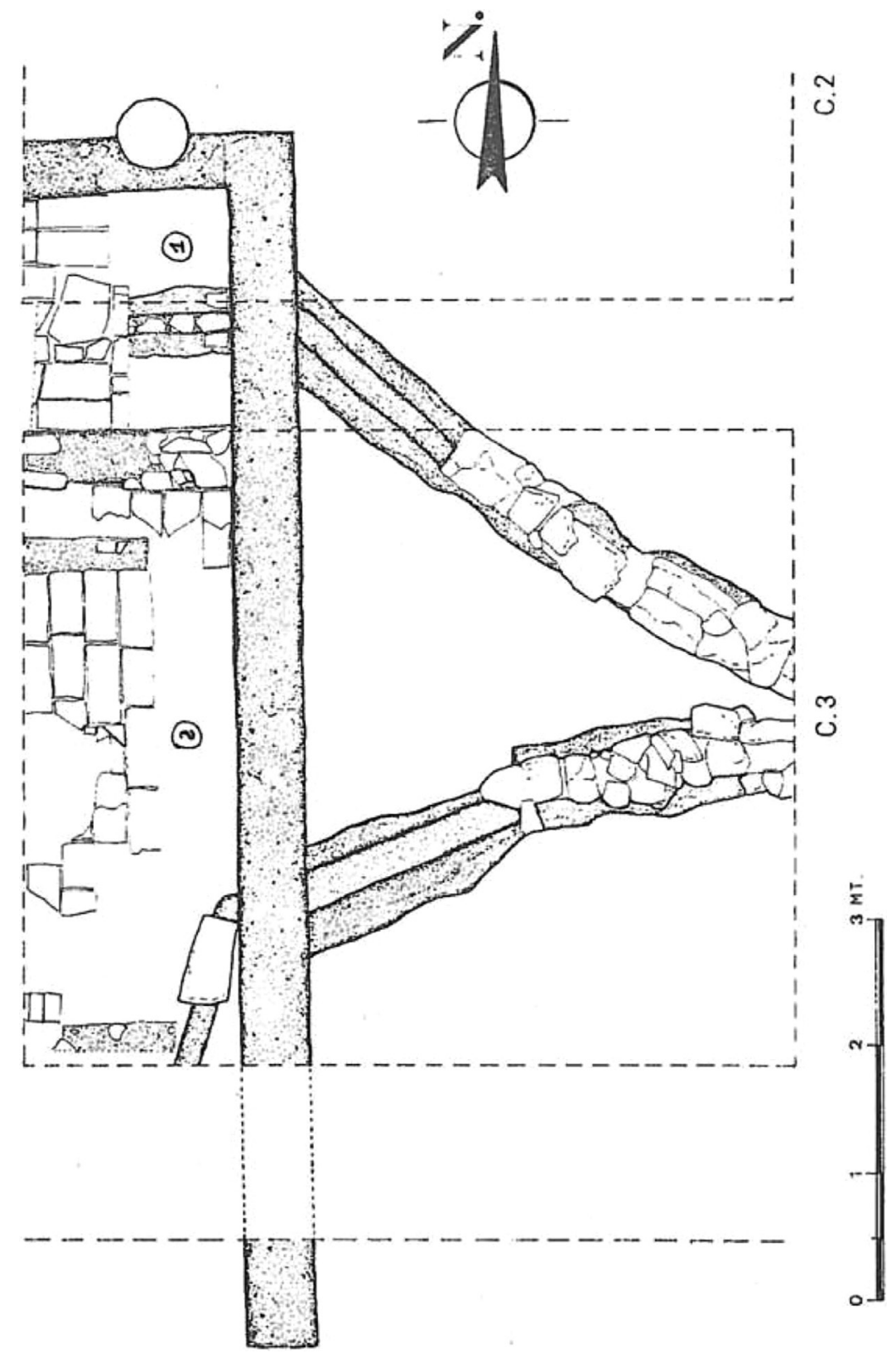

Fig. 12. Planta de los restos hallados en la calle Montijo no 8 (BERNAL, JIMÉNEZ, 1993: 395)

contaban con un pavimento de piedra labrada. En el exterior del edificio y asociadas a estas dos salas se documentaron dos atarjeas con cubierta de lajas de pizarra que desaguaban hacia el este hasta confluir en un mismo punto. La canalización ubicada al norte desaguaba la letrina y la situada al sur desaguaba la otra sala. La zona por la que discurren las atarjeas ha sido interpretada como una calle o un espacio abierto. El estudio del material cerámico permitió establecer el siglo XII como marco cronológico de estas estructuras. Este edificio se ubicaba en la calle paralela a uno de los ejes viales principales de la ciudad, que la recorría de este a oeste, conformado por las actuales calles Selgas, San Cristóbal y Platería. En esta calle, próximos a los restos documentados, se ubicaba el granero andalusí, una mezquita y un baño.

Los arqueólogos plantearon que estos restos no formaban parte de una vivienda sino de una 


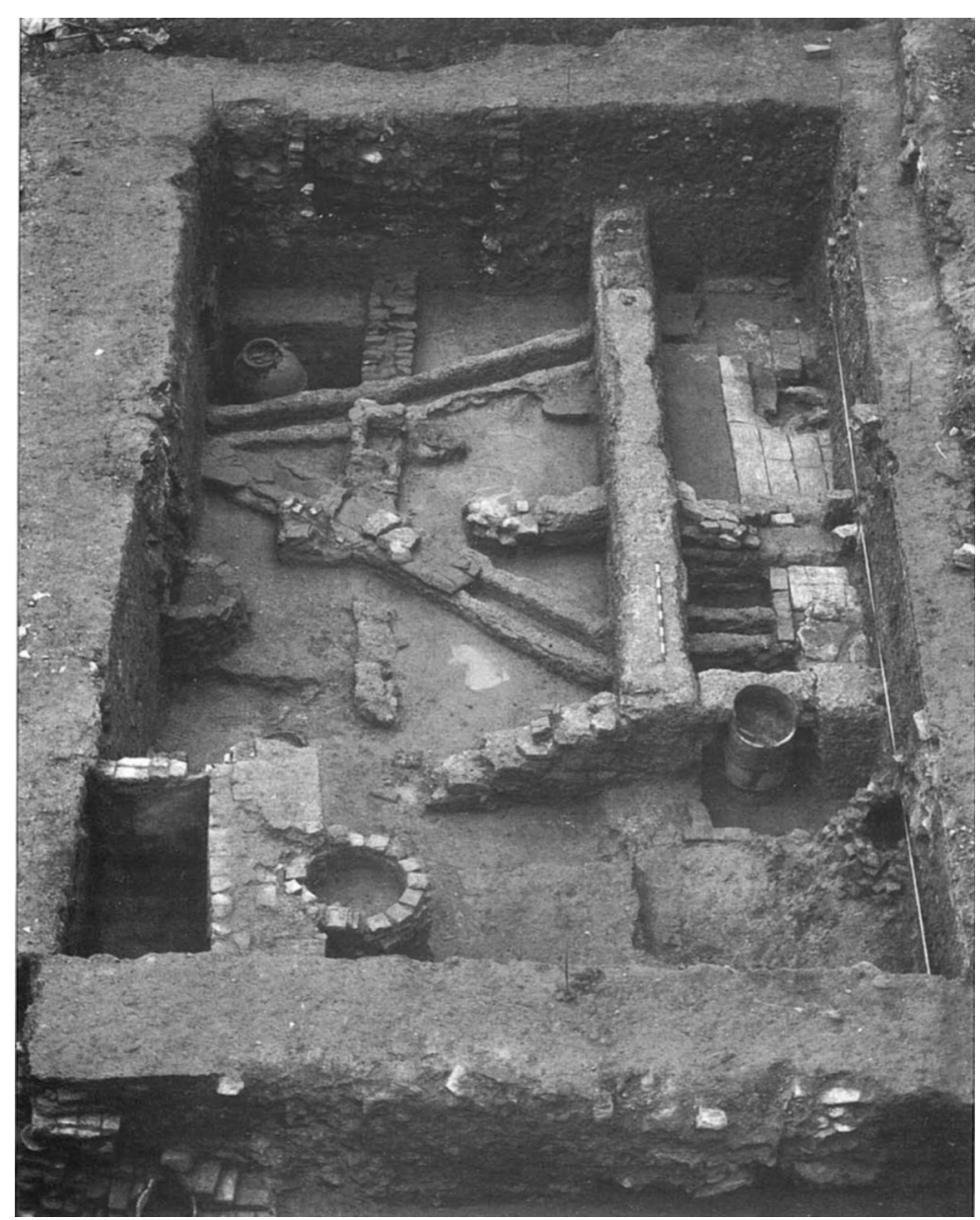

Fig. 13. Fotografía de los restos hallados en la calle Montijo no 8 (BERNAL, JIMÉNEZ, 1993: 397)

zona de servicio de un edificio público de importancia por la calidad de los pavimentos documentados y establecieron que el edificio se mantuvo en uso posteriormente por los canales de evacuación hallados, aunque no pudieron asociarlos a estructuras internas del edificio pues habían sido arrasadas por cimentaciones modernas (BERNAL, JIMÉNEZ, 1989: 7). Además, la disposición del sistema hidráulico del edificio, la posibilidad de que se tratara de dos letrinas contiguas, y la compartimentación de la crujía ha llevado a I. Reklaityte (2012: 201) a plantear que se tratara de un edificio de carácter público o semipúblico.

Sin duda, los exiguos restos del inmueble no permiten plantear con seguridad una única interpretación. Sin embargo, la estructuración de la crujía documentada, su relación con un sistema hidráulico más complejo que el de una vivienda y su ubicación en el entramado urbano de la Murcia andalusí nos llevan a plantear la posibilidad de que los restos de este edificio pudieran haber formado parte de un funduq.

Por último, trataremos los restos hallados en una excavación realizada en 2003 en un solar ubicado en el cruce de las actuales calles Granero y Alejandro Séiquer, en la que se documentaron tres viviendas andalusíes con una cronología de fases de uso entre los siglos XI y XIII y una estructura anexa a estas (ZAPATA, FERNÁNDEZ, 2005). En concreto, centraremos nuestra atención en el denominado "anexo casa 1" (Figuras 14 y 15), identificado como un edificio anexo al que se adosaban las estructuras de la casa 1 y al que se le adscribió un carácter civil o público por sus dimensiones. Se trata de un muro medianero de tapial de mortero de cal con una longitud de 14,30 m y 


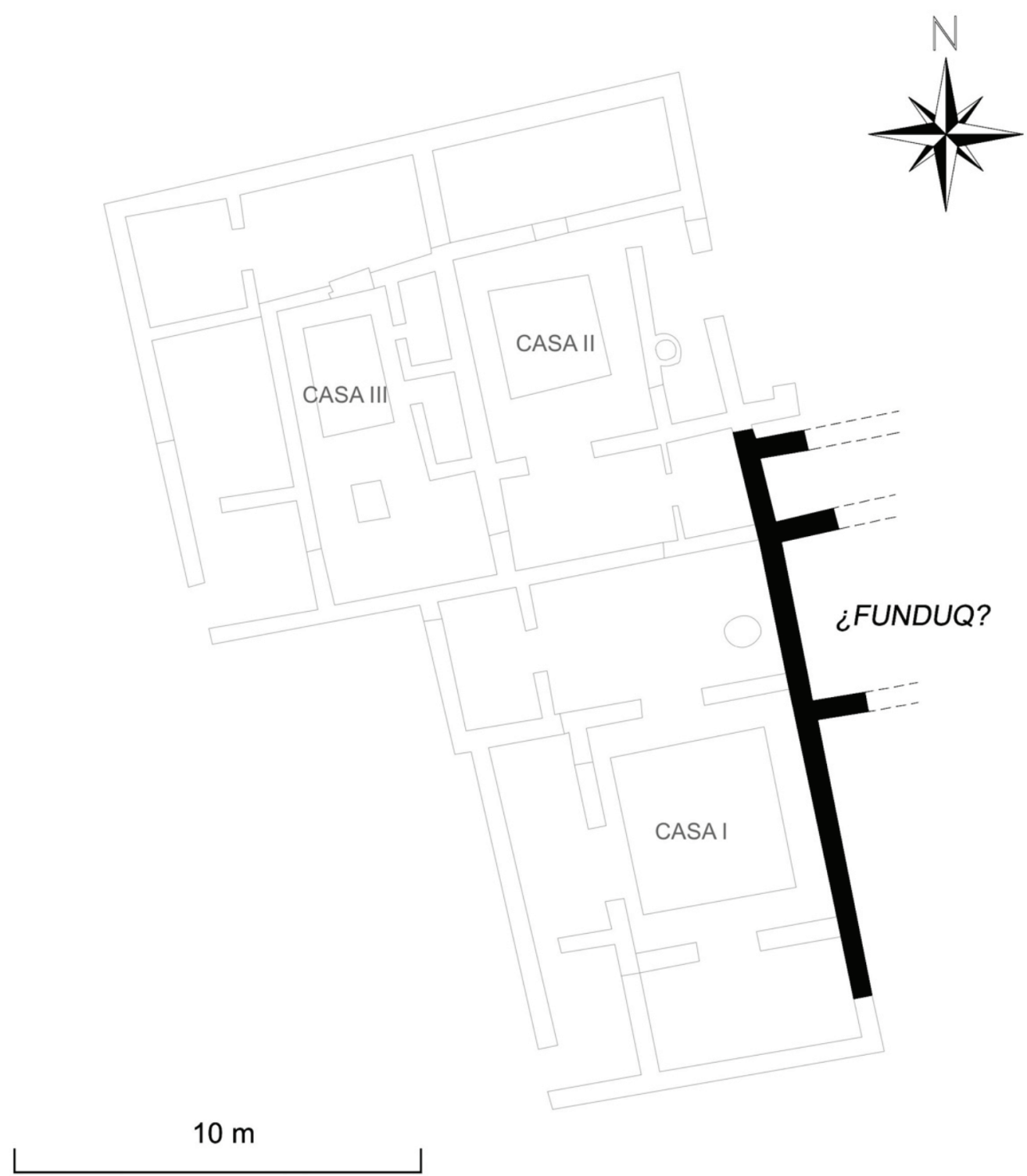

Fig. 14. Planta del edificio anexo a la casa I de la excavación de la calle Granero (Elaborado por José Gabriel Gómez (arrasco).

una anchura de 0,40 m que cerraría el edificio en su lado oeste y tres muros que se le adosan de forma transversal dando como resultado la configuración de tres espacios en el interior. El espacio ubicado más al norte tenía una longitud de 2,20 m, el intermedio 4,05 m y el espacio sur unos $7 \mathrm{~m}$.

Los arqueólogos propusieron varias hipótesis para interpretar estos restos. Plantearon que se tratara de la crujía occidental de una gran casa de tipo palacial, que los restos formaran parte de la mezquita ubicada en la collación de San Lorenzo o que se tratara de los restos de una alhóndiga o funduq cuyo acceso se ubicaría en la calle Saavedra Fajardo, frente al granero islámico (ZAPATA, FERNÁNDEZ, 2005: 250). La propuesta de interpretación de estos restos como parte de un edificio público y comercial fue argumentada por las grandes dimensiones del edificio documentado parcialmente y su ubicación en el urbanismo de la ciudad de Murcia. El inmueble se ubicaba en el barrio de San Lorenzo, próximo al granero islámico de la ciudad y junto a uno de los ejes viales principales que atravesaban la 


\section{*}

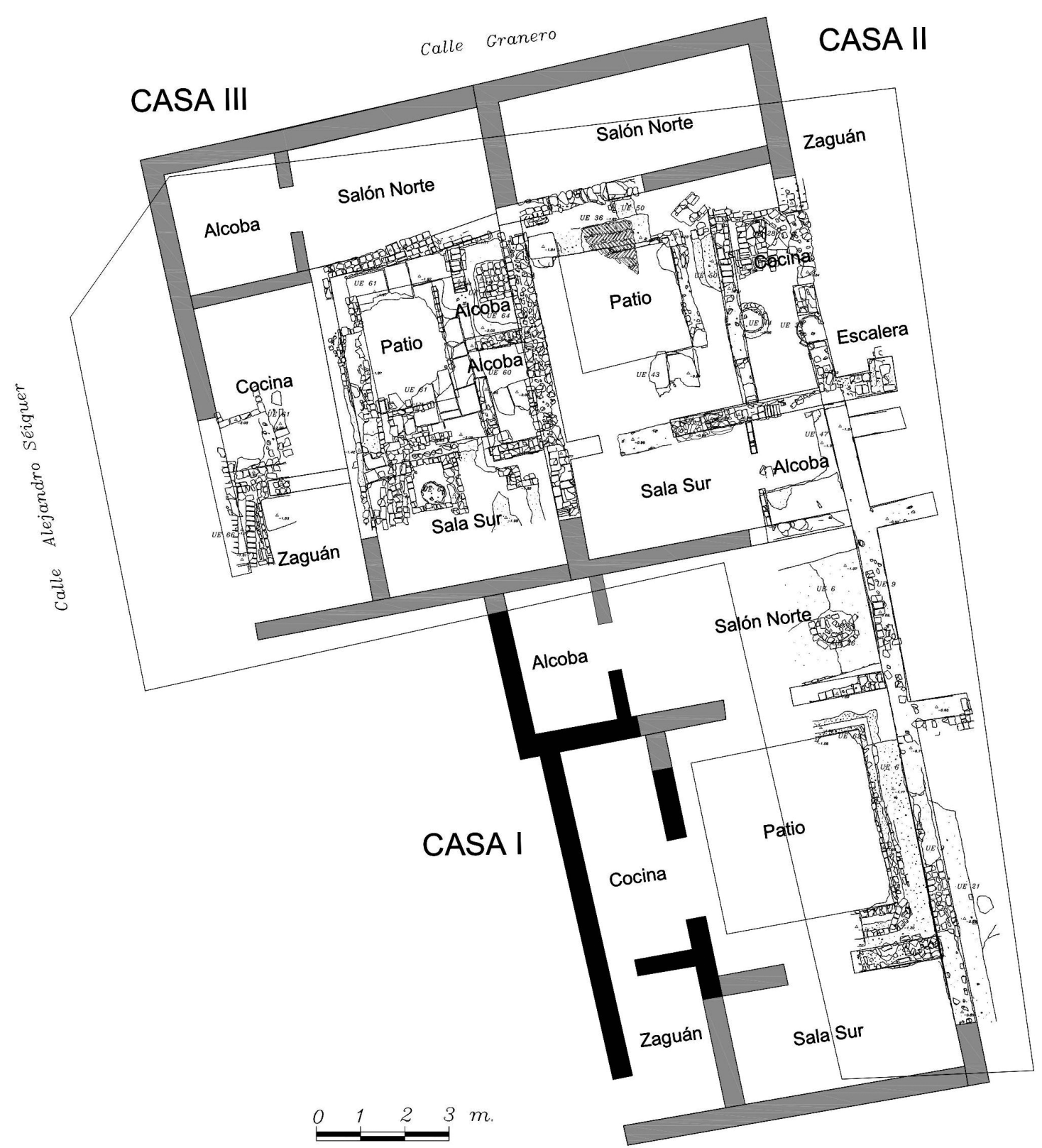

Fig. 15. Plano del solar excavado en la calle Granero (ZAPATA, 2010: 11).

medina en dirección norte-sur, cuyo trazado conservan en la actualidad las actuales calles Rambla y Alejandro Séiquer, antes conocida como calle del Zoco, pues uno de los zocos de la ciudad se ubicaba al final de esta calle. Además, al sur del solar de la excavación se ubicaría una mezquita, ahora actual iglesia de San Lorenzo, y en sus proximidades, en otra manzana al oeste del solar excavado, en el cruce de la calle San Lorenzo con la calle del Zoco, se identificaron los restos de un baño.

Ante la escasez de restos documentados de este edificio, cuyas estructuras se prolongan hacia el este bajo las construcciones colindantes, no nos aventuramos a confirmar 
o rechazar que dichas estructuras formaran parte de un funduq o de otro tipo de edificio público. Sin duda se trataría de un edificio de grandes dimensiones, cuya funcionalidad no podemos precisar. Sin embargo, estamos de acuerdo con la interpretación realizada por los arqueólogos del urbanismo andalusí de esta zona de la ciudad, pues cumple con las características ideales para la ubicación de un funduq: en una calle principal o próximo a ella, así como a una de las puertas por la que se accedía a la ciudad, junto a un baño y una mezquita.

\section{CONCLUSIONES}

De los siete posibles fanādiq murcianos consideramos que cuatro de ellos, los edificios de la Plaza Belluga, del conjunto arqueológico de San Esteban, de la excavación Garaje Villar y los restos parciales del edificio de la Plaza de Santa Eulalia, funcionaron como funduq en época andalusí. En cuanto a los restos parcialmente documentados de las calles Montijo y Granero, consideramos que los restos de la calle Montijo podrían haber tenido esta funcionalidad al tratarse de un edificio de grandes dimensiones con sistema de canalizaciones. Sin embargo, no han podido documentarse más aspectos que permitan identificarlo con total seguridad. Los restos de la calle Granero plantean más dudas, dado que apenas pudo documentarse más que el muro medianero del edificio y el arranque de tres muros divisorios. En consecuencia, no ha habido posibilidad de conocer realmente su disposición interna o la funcionalidad de alguna de sus estancias. Se ha propuesto que los restos formen parte de la crujía occidental del edificio aunque no podemos descartar que se trate del límite norte del mismo y que las estructuras marcaran una doble crujía norte y señalaran la ausencia de una crujía occidental, lo que lo alejaría de la planta de estos edificios, en los que las crujías de los lados este y oeste tienen un mayor protagonismo en comparación con estas crujías en grandes viviendas residenciales andalusíes, en las que las crujías sur y norte son las principales. Por último, de acuerdo a los motivos expuestos, descartamos que los restos hallados en la confluencia de las calles Pascual y Conde Valle de San Juan formaran parte de un funduq.

Todos los casos de estudio murcianos configuran edificios de grandes dimensiones con una de sus crujías compartimentada en espacios de dimensiones más reducidas. Además, en los edificios de la Plaza Belluga, Garaje Villar y la Plaza de Santa Eulalia las crujías este u oeste se extienden hacia los extremos norte y sur ocupando los extremos del edificio. Entre los edificios de San Esteban y la Plaza de Santa Eulalia se han identificado ciertas similitudes, como su distribución en torno a un patio central porticado en su lado norte. La planta de los edificios murcianos contrasta con otros fanādiq andalusíes mencionados en los que las cuatro crujías aparecían divididas de forma similar, como algunos de Córdoba o Denia (CLAPÉS, 2014-2015, GISBERT, 2003, 2014). Sin embargo, los casos de estudio murcianos podemos relacionarlos con los fanādiq andalusíes que presentan tanto crujías compartimentadas como espacios sin divisiones internas, por ejemplo, con alguno de los edificios de Córdoba y el funduq de Valencia (CAMACHO, VALERA, 2020: 131 y 133; MARTÍ, BURRIEL, 2008).

En cuanto al sistema hidráulico que presentan los fanādiq de Murcia encontramos una configuración de varios canales de evacuación en los edificios de la Plaza Belluga, el conjunto arqueológico de San Esteban y la calle Montijo, mientras que se ha documentado al menos una atarjea en los restos de la Plaza de Santa Eulalia y Garaje Villar. Solo en el edificio de la Plaza Belluga y en el del conjunto arqueológico San Esteban se han documentado letrinas colectivas, mientras que en los edificios de la Plaza de Santa Eulalia y la calle Montijo se ha identificado una letrina. Con respecto a otras características del sistema hidráulico de los fanādiq debemos mencionar que solo en el edificio del conjunto arqueológico de San Esteban se ha documentado un pozo en uno de los espacios de la crujía oeste.

La interpretación de algunos espacios como zonas de servicio, como posible zona de cocina o de producción artesanal ha sido 
documentada con la existencia de estructuras de combustión en el "Recinto I" del conjunto arqueológico de San Esteban y en el "Espacio 4" de Garaje Villar.

Con respecto a la ubicación de estos edificios en la medina de Murcia, excepto el funduq documentado en el arrabal de la Arrixaca, el resto de edificios los encontramos en torno a las dos vías principales que recorrían la ciudad de Murcia de este a oeste, por un lado, los restos de la Plaza Belluga y de la Plaza de Santa Eulalia se encuentran en la vía que actualmente componen las calles San Pedro, Frenería y San Antonio. Estos dos edificios se encontraban próximos a puertas de la ciudad y mezquitas, el de la Plaza Belluga a la puerta del Sol y la puerta del Puente, la principal de la ciudad, y junto a la mezquita aljama, y el de la Plaza de Santa Eulalia próximo a la puerta de Santa Eulalia y a una mezquita cercana que habría ocupado el espacio de la actual iglesia de Santa Eulalia. Por otro lado, encontramos los restos de las excavaciones Garaje Villar y calle Montijo próximos a la vía que actualmente componen las calles Selgas, San Cristóbal y Platería. Sin embargo, su ubicación no parece prolongarse a lo largo de su recorrido, sino que se encuentran próximos a la intersección de esta vía con la calle Alejandro Séiquer, antes conocida como calle del Zoco, que forma parte de uno de principales ejes viales andalusíes que recorrían la ciudad de Murcia de norte a sur ${ }^{4}$. Aunque la ubicación en el entramado urbano de los restos de la calle Granero, próximos a la calle Alejandro Séiquer, es idónea para la localización de un funduq, los restos son muy escasos para plantear una interpretación firme. En las proximidades de estos edificios también se han documentado en Murcia restos arqueológicos de baños que pudieron ser utilizados por los usuarios de estos fanādiq. El edificio de la Plaza Belluga se ubicaba próximo a los baños de la calle Madre de Dios. El baño de San Antonio se ubicaba próximo a los restos de la Plaza de Santa Eulalia y los edificios de Garaje Villar y la calle
Montijo se encontraban próximos al baño de San Lorenzo.

En consecuencia, podemos interpretar que estos edificios se ubicaban en espacios transitados de la ciudad, en calles principales y/o cerca de sus puertas, y próximos a mezquitas, puntos clave en las ciudades andalusíes para el trasiego de mercancías y personas. Esta ubicación privilegiada en el entramado urbano se complementa con la presencia de baños próximos a estos edificios, y que podrían haber sido utilizados por los viajeros o comerciantes del funduq. En la Figura 16 contextualizamos la presencia de los edificios interpretados como fanādiq en el urbanismo de la ciudad de Murcia localizando estos en el plano de la ciudad y los edificios con los que se suele asociar su ubicación, también documentados arqueológicamente en las últimas décadas: mezquitas, baños y tiendas.

En definitiva, para la interpretación de estos restos arqueológicos de la ciudad de Murcia como fanādiq se han combinado las características propias de la distribución interna de los edificios y su ubicación en el entramado urbano de la medina y su arrabal, relación que ha sido planteada en otros estudios arqueológicos y en el estudio histórico de los fanādiq islámicos. La construcción de estos edificios en determinadas ciudades de al-Andalus serviría para satisfacer la necesidad de ofrecer un espacio seguro y controlado a las viajeros, comerciantes y mercancías que llegaran a ciudades en las que el comercio constituyera una importante actividad económica.

\section{BIBLIOGRAFÍA}

ARROYO PÉREZ, E., PÉREZ TORRES, C., FRESNEDA PADILLA, E., LÓPEZ LÓPEZ, M. y PEÑA RODRÍGUEZ, J. M. (1995): "Excavación arqueológica de urgencia en la alhóndiga Zayda en Puerta RealCalle Mesones (Granada)", Anuario arqueológico de Andalucía 1992, pp. 279-283.

BERNAL PASCUAL, F. y JIMÉNEZ CASTILLO, P. (1989): Informe de los trabajos arqueológicos realizados en el solar de C/Montijo $n^{\circ} 8$. Informe depositado en el Archivo General de la Región de Murcia, expte. $n^{0} 8552 / 8$.

\footnotetext{
4. Remitimos a los trabajos de Torres (1960), Roselló, Cano (1975), García (1980) y Pocklington (1989).
} 


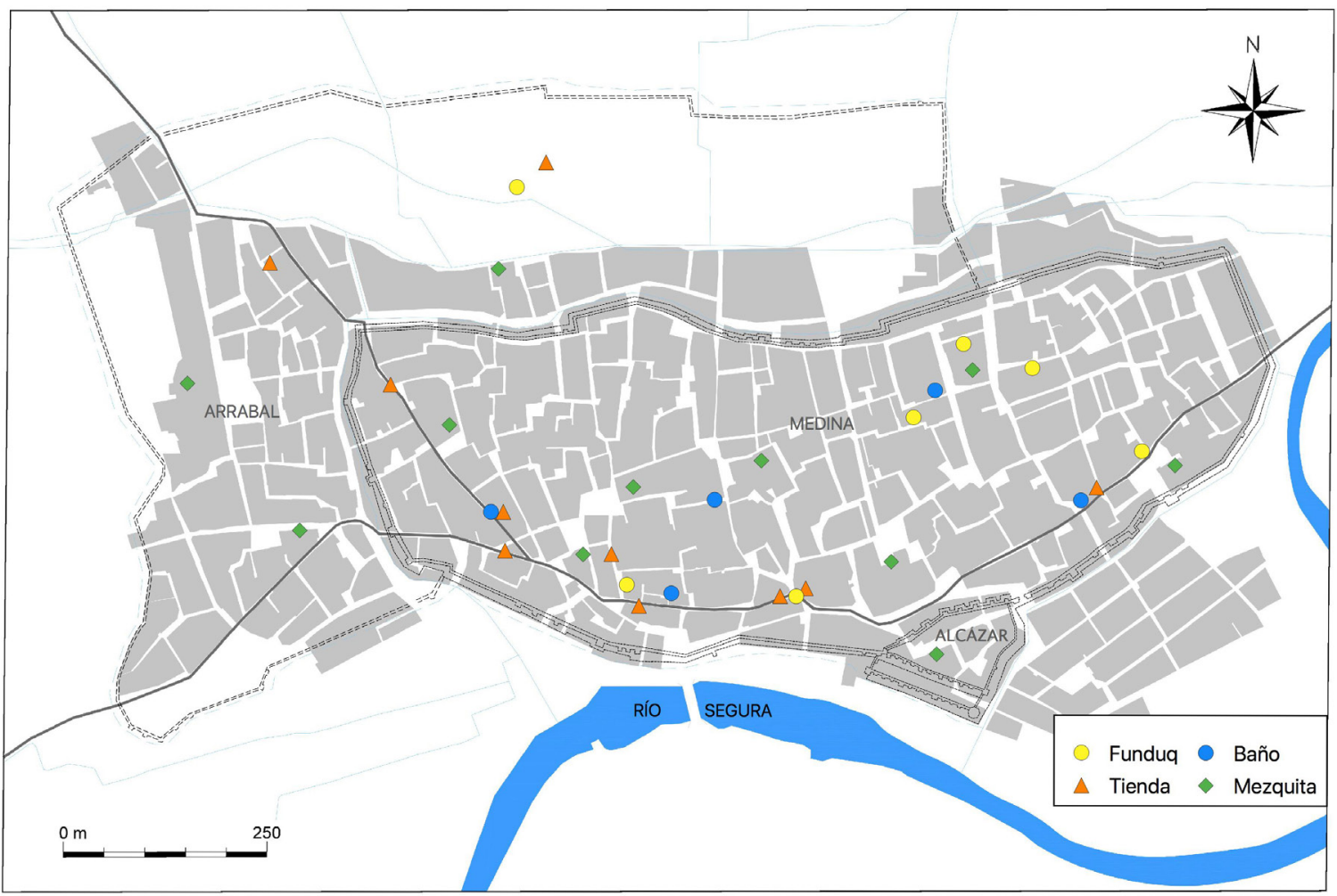

Fig. 16. Plano de ubicación de fanādiq, tiendas, baños y mezquitas en Murcia. Con una línea continua aparecen señaladas las calles principales de la ciudad (Elaboración propia a partir del plano base de José Gabriel Gómez Carrasco).

BERNAL PASCUAL, F.y JIMÉNEZ CASTILLO, P. (1993): "Excavaciones arqueológicas de urgencia: C/Montijo, 8 (Murcia). Memoria preliminar", Memorias de Arqueología (1989), 4, pp. 389-401.

BUENDÍA MORENO, A. F.y ÁLVAREZ GARCÍA, J. J. (2010): “Un posible funduq nazarí. Intervención arqueológica puntual en el Teatro Cine Imperial de Loja (2006)", Anuario Arqueológico de Andalucía 2006, pp. 1344-1348.

CAMACHO CRUZ, C. y VALERA PÉREZ, R. (2020): "Edificios comerciales de los arrabales occidentales de Madinat Qurtuba: un acercamiento desde la arqueología virtual", ANTIQVITAS, 32, pp. 127-142.

CARA BARRIONUEVO, L., GARCÍA LÓPEZ, J. L. y MORALES SÁNCHEZ, R. (2000): "Arqueología urbana e historia de la ciudad. E caso de Almería medieval", en L. Cara Barrionuevo (ed.), Ciudad y territorio en al-Andalus, pp. 167-192. Granada: Athos-Pérgamos.

CARA BARRIONUEVO, L. y MORALES SÁNCHEZ, R. (2006): "Instalaciones industriales en la Almería medieval", Anuario Arqueológico de Andalucía 2003.III, pp. 36-46.

CASAL GARCÍA, M. T. (2020): "Contextos arqueológicos en el arrabal omeya de Šaqunda: el funduq", en C. Doménech Belda y S. Gutiérrez Lloret (eds.), El sitio de las cosas. La Alta Edad Media en contexto, pp. 235-254. Alicante: Universidad de Alicante.

CASAL GARCÍA, M. T. et al. (2006): "Informe-Memoria de la I.A.U. en el S.G. SS-1 (Parque de Miraflores y Centro de Congresos de Córdoba). Segunda fase", Anuario arqueológico de Andalucía 2003, pp. 343-356.
CASTRO DEL RIO, E. (2005): El arrabal de época califal de la zona arqueológica de Cercadilla: la arquitectura doméstica. Córdoba: Universidad de Córdoba.

CHALMETA GENDRÓN P. (1973): El «señor del zoco» en España: edades media y moderna: contribución al estudio de la historia del mercado. Madrid: Instituto Hispano-Árabe de Cultura.

CHALMETA GENDRÓN, P. (2010): El zoco medieval. Contribución al estudio de la historia del mercado. Almería: Fundación Ibn Tufayl de Estudios Árabes.

CLAPÉS SALMORAL, R. (2014-2015): "La actividad comercial de Córdoba en época califal a través de un edificio hallado en el arrabal de poniente", Anales de Arqueología Cordobesa, 25-26, pp. 225-254.

CONSTABLE, O. R. (2003): Housing the Stranger in the Mediterranean World. Cambridge, Reino Unido: Cambridge University Press.

EIROA RODRÍGUEZ, J., HABER URIARTE, M., VALLALTAMARTíNEZ, P., GONZÁLEZ BALLESTEROS, J. A., HERNÁNDEZ ROBLES, A., CELMA MARTÍNEZ, M., MARTÍNEZ RODRÍGUEZ, A. L., MUÑOZ ESPINOSA, M. A., SALAS ROCAMORA, S. y MOLINA CAMPUZANO, M. I. (2019): "El conjunto arqueológico de San Esteban: aportaciones desde la investigación interdisciplinar", en XXV Jornadas de Patrimonio Cultural de la Región de Murcia, pp. 41-51. Murcia: Tres Fronteras Ediciones.

FLORIDO ESTEBAN, D. D. et al. (2010): "Intervención arqueológica en el yacimiento del Llano de Torroba, Rincón de la Victoria", Anuario Arqueológico de Andalucía 2006. Málaga, pp. 3305-3310. 
GARCíA ANTÓN, J. (1980): "La Región de Murcia en tiempos del Islam", en F. Chacón Jiménez (dir.), Historia de la Región Murciana, T. III, pp. 9-33. Murcia: Ediciones Mediterráneo.

GISBERT SANTONJA, J. A. (2003): "Una proposta de museaïtzació i gestió del funduq islàmic de la Medina de Daniya, Dénia”, en J. Beltrán de Heredia e I. Fernández (coords.), II Congreso Internacional sobre musealización de yacimientos arqueológicos: nuevos conceptos y estrategias de gestión y comunicación, pp. 74-82. Barcelona: Museu d'Història de la Ciutaty Ayuntamiento de Barcelona.

GISBERT SANTONJA, J. A. (2007): "Daniya, reflejo del Mediterráneo: una mirada a su urbanismo y arqueología desde el mar (siglo XI)", en A. Suárez (coord.), 2007, Almería, "puerta del Mediterráneo (ss. X-XII)", pp. 203-230. Almería: Junta de Andalucía. Consejería de Cultura.

GISBERT SANTONJA, J. A. (2014): "La ciudad y la cocina. Manifestaciones urbanas. 1000 años. Una ciudad de fondacs \& alhóndigas", El paraíso culinario de Daniya, en lamarinaplaza.com, 21 de diciembre de 2014. Recuperado de: http://lamarinaplaza. com/2014/12/21/el-paraiso-culinario-de-daniya/.

GISBERT SANTONJA, J. A. (2020): "Una investigación detecta 7 «hoteles» de época islámica en Dénia, más que en ninguna otra ciudad del país", en lamarinaplaza.com, 10 de febrero de 2020 Recuperado de: https://lamarinaplaza.com/2020/02/10/ una-investigacion-detecta-7-hoteles-de-la-era-islamicaen-denia-mas-que-en-ninguna-otra-ciudad-del-pais/.

Î̃IIGUEZ SÁNCHEZ, M. C. (2010): "De la Málaga emiral a la nazarí. IAP. En las calles Sebastián Souvirón, Olózaga y Marqués (Málaga)", Anuario Arqueológico de Andalucía 2006. Málaga, pp. 3398-3425.

JIMÉNEZ CASTILLO, P. (2013): Murcia. De la Antigüedad al Islam. Tesis doctoral. Granada: Universidad de Granada.

JIMÉNEZ CASTILLO, P. y NAVARRO PALAZÓN, J. (2001): "Murcia Omeya", en M. J. Viguera y C. Castillo (coords.), El esplendor de los Omeyas Cordobeses: la civilización musulmana de Europa occidental, pp. 132-151. Granada: El Legado Andalusí.

JIMÉNEZROLDÁN, M.C. (2019): "Del funduqa laalhoóndiga: unespacio entre el emirato nazaríy el reino de Granada (s. XV-XVI)", al-Qantara, 40, 2, pp. 315-354. https://doi.org/10.3989/alqantara. 2019.010

MANZANO MARTÍNEZ, J. (1995): "Memoria preliminar de los trabajos arqueológicos realizados en el subsuelo de la actual plaza de Europa (Antiguo Garaje Villar). Ciudad de Murcia", Memorias de Arqueología (1987-1988), 3, pp. 354-397.

MARTí OLTRA, J. y BURRIEL ALBERICH J. (2008): "Comerciar en tierra extraña. La alhóndiga musulmana de la calle Corretgeria de Valencia", en Historia de la ciudad V. Tradición y progreso, pp. 41-60. Valencia: Colegio Oficial de Arquitectos de la Comunidad Valenciana y Colegio Territorial de Arquitectos de Valencia.

NAVARRO PALAZÓN, J. y JIMÉNEZ CASTILLO, P. (1994): “Una nueva propuesta de investigación y gestión de yacimientos urbanos: la ciudad de Murcia", en Paisajes rurales y paisajes urbanos: métodos de análisis en historia medieval. pp. 157-203. Zaragoza: Universidad de Zaragoza.

NAVARRO PALAZÓN, J. y JIMÉNEZ CASTILLO, P. (2002): "Casas y tiendas en la Murcia andalusí. Excavación en el solar municipal de la Plaza de Belluga", Memorias de Arqueología (1995), 10, pp. 490-532.
ORIHUELA UZAL, A. (1995): "Granada, capital del Reino Nazarí", en R. López Guzmán (coord.), La arquitectura del Islam Occidental, pp. 195- 209. Barcelona: Lunwerg.

PERAL BEJARANO, C. y Î̃IIGUEZ SÁNCHEZ, C. (2016): "El Castell de Genoveses. Una colonia de época nazarí en la plaza de la Marina de Málaga", Mainake, 36, pp. 365-394.

POCKLINGTON, R. (1989): "Nuevos datos sobre cinco puertas musulmanas y una torre de la cerca medieval de Murcia", en F. J. Flores Arroyuelo (coord.), Murcia musulmana, pp. 215-232. Murcia: Ediciones Almudí.

REKLAITYTE, I. (2012): Vivir en una ciudad de al-Andalus. Hidráulica, saneamiento y condiciones de vida. Zaragoza: Universidad de Zaragoza.

ROBLES FERNÁNDEZ, A., SÁNCHEZ PRAVIA, J. A. y NAVARRO SANTA-CRUZ, E. (2011): "Arquitectura residencial andalusí y jardines en el arrabal de la Arrixaca. Breve síntesis de las excavaciones arqueológicas realizadas en el jardín de San Esteban, Murcia (2009)", Verdolay, 13, pp. 205-219.

ROLDÁN MEDINA, F. J., REINOSO GORDO, J. F. y GÓMEZ-BLANCO PONTES, A. J. (2020): "Registro y parametrización antropométrica del patrimonio arquitectónico: el Corral del Carbón de Granada", Informes de la Construcción, 72(558): e337, pp. 1-11. https://doi. org/10.3989/ic.72000

ROSELLÓ, V. M. y CANO, G. M. (1975): Evolución urbana de la ciudad de Murcia: 831-1973. Murcia: Ayuntamiento de Murcia.

RUIZ PARRA, I. (1990): Informe preliminar excavaciones arqueológicas $n^{\circ} 4$ y 6 de la C/Pascual. Informe depositado en el Archivo General de la Región de Murcia, expte. $n^{0}$ 30197/9 y expte. $n^{0}$ 8574/48.

RUIZ PARRA, I. (1996): "Excavaciones arqueológicas en el solar de la C/ Conde Valle de San Juan, esquina C/ Pascual de Murcia", Memorias de Arqueología (1990), 5, pp. 415-426.

SALADO ESCAÑO, J. B. y ALTAMIRANO TORO, E. (2011): Memoria definitiva de la intervención arqueológica preventiva en el edificio de Félix Sáenz, n4, Málaga. $2^{\circ}$ fase. Memoria depositada en la Delegación Territorial de Cultura y Patrimonio Histórico en Málaga, expte. 43/09.

TORRES BALBÁS, L. (1946): "Las alhóndigas hispano-musulmanasy el corral del carbón de Granada", Al-Andalus, 11, pp. 446-480.

TORRES FONTES, J. (1960): Repartimiento de Murcia. Murcia: Escuela de Estudios Medievales. Academia Alfonso Xel Sabio de Murcia.

VÁZQUEZ NAVAJAS, B. (2016): Arqueología hidráulica en los arrabales occidentales de la Córdoba omeya. Tesis doctoral. Córdoba: Universidad de Córdoba.

ZAPATA PARRA, J. A. (2010): Evolución urbana de tres viviendas andalusíes en la calle Granero - Alejandro Séiquer de Murcia. Tesis de Máster. inédita. Murcia: Universidad de Murcia.

ZAPATA PARRA, J. A. y FERNÁNDEZ MATALLANA, F. (2005): “Urbanismo islámico: tres casas en la calle Granero de Murcia (siglos XIIXIII)", Verdolay, 9, pp. 233-254. 